\title{
Regional pollution potentials of megacities and other major population centers
}

\author{
M. G. Lawrence ${ }^{1}$, T. M. Butler ${ }^{1}$, J. Steinkamp ${ }^{1}$, B. R. Gurjar ${ }^{2}$, and J. Lelieveld ${ }^{1}$ \\ ${ }^{1}$ Max-Planck-Institut für Chemie, P.O. Box 3060, 55020 Mainz, Germany \\ ${ }^{2}$ Indian Institute of Technology Roorkee, Department of Civil Engineering, Roorkee 247667, India
}

Received: 1 December 2006 - Published in Atmos. Chem. Phys. Discuss.: 19 December 2006

Revised: 13 June 2007 - Accepted: 23 July 2007 - Published: 26 July 2007

\begin{abstract}
Megacities and other major population centers represent large, concentrated sources of anthropogenic pollutants to the atmosphere, with consequences for both local air quality and for regional and global atmospheric chemistry. The tradeoffs between the regional buildup of pollutants near their sources versus long-range export depend on meteorological characteristics which vary as a function of geographical location and season. Both horizontal and vertical transport contribute to pollutant export, and the overall degree of export is strongly governed by the lifetimes of pollutants. We provide a first quantification of these tradeoffs and the main factors influencing them in terms of "regional pollution potentials", metrics based on simulations of representative tracers using the 3-D global model MATCH (Model of Atmospheric Transport and Chemistry). The tracers have three different lifetimes (1, 10, and 100 days) and are emitted from 36 continental large point sources. Several key features of the export characteristics emerge. For instance, long-range nearsurface pollutant export is generally strongest in the middle and high latitudes, especially for source locations in Eurasia, for which $17-34 \%$ of a tracer with a 10-day lifetime is exported beyond $1000 \mathrm{~km}$ and still remains below $1 \mathrm{~km}$ altitude. On the other hand, pollutant export to the upper troposphere is greatest in the tropics, due to transport by deep convection, and for six source locations, more than $50 \%$ of the total mass of the 10-day lifetime tracer is found above $5 \mathrm{~km}$ altitude. Furthermore, not only are there order of magnitude interregional differences, such as between low and high latitudes, but also often substantial intraregional differences, which we discuss in light of the regional meteorological characteristics. We also contrast the roles of horizontal dilution and vertical mixing in reducing the pollution buildup in the regions including and surrounding the sources. For some regions such as Eurasia, dilution due to long-range horizontal transport
\end{abstract}

Correspondence to: M. G. Lawrence

(lawrence@mpch-mainz.mpg.de) governs the local and regional pollution buildup; however, on a global basis, differences in vertical mixing are dominant in determining the pollution buildup both around and further downwind of the source locations.

\section{Introduction}

For the past few thousand years, human populations have been clustering in increasingly large settlements. At present, there are about 20 cities worldwide with a population of ten million or greater (see Table 1), and 30 with a population of about 7 million or greater. These numbers are expected to grow considerably in the near future. This confluence of human activity in so-called "megacities" (e.g. Molina and Molina, 2004) leads to serious issues in municipal management, such as the coordination of public and private transport, solid and liquid waste disposal, and local air pollution. The latter is known to have significant local and regional consequences for human health and crop production (e.g. Chameides et al., 1994; Emberson et al., 2001). On the other hand, emissions of longer-lived pollutants from these concentrated population centers can affect atmospheric chemistry on the continental and global scale. The balance between local and long-range effects can be anticipated to depend strongly on regional meteorological and geographical differences. Here we address the question: What are the common features and differences in the regional and long-range dispersion characteristics for air pollutants emitted from large, concentrated urban sources?

We examine this issue using representative, artificial tracers in a global 3-D chemistry-transport model (CTM). Three tracers with exponential decay lifetimes of 1,10 , or 100 days are emitted from each of 36 selected major population centers. These can be applied generically towards understanding the anticipated typical outflow characteristics of a wide range of trace gases and aerosols. For instance, the typical

Published by Copernicus Publications on behalf of the European Geosciences Union. 
Table 1. The set of selected MPC source locations and their approximate populations (projections for 2005), along with the corresponding longitudes and latitudes as employed in the model setup.

\begin{tabular}{|c|c|c|c|}
\hline City & $\begin{array}{l}\text { Population }^{1} \\
\left(\times 10^{6}\right)\end{array}$ & Lon $^{2}$ & $\mathrm{Lat}^{2}$ \\
\hline \multicolumn{4}{|l|}{ Eurasia } \\
\hline London, England & 7.6 & 0.0 & 51.3 \\
\hline Paris, France & 9.9 & 1.9 & 49.4 \\
\hline Moscow, Russia & 10.7 & 37.5 & 55.0 \\
\hline Po Valley, Italy & $>6.0^{3}$ & 11.2 & 45.7 \\
\hline Istanbul, Turkey & 9.8 & 28.1 & 40.1 \\
\hline Teheran, Iran & 7.4 & 50.6 & 34.5 \\
\hline \multicolumn{4}{|l|}{ Africa } \\
\hline Cairo, Egypt & 11.1 & 31.9 & 28.9 \\
\hline Lagos, Nigeria & 11.1 & 3.8 & 6.5 \\
\hline Johannesburg, South Africa & 3.3 & 28.1 & -27.0 \\
\hline \multicolumn{4}{|l|}{ Southern Asia } \\
\hline Karachi, Pakistan & 11.8 & 67.5 & 25.2 \\
\hline Mumbai, India & 18.3 & 73.1 & 19.6 \\
\hline Delhi, India & 15.3 & 76.9 & 28.9 \\
\hline Kolkata, India & 14.3 & 88.1 & 23.3 \\
\hline Dhaka, Bangladesh & 12.6 & 90.0 & 23.3 \\
\hline \multicolumn{4}{|l|}{ Eastern Asia } \\
\hline Szechuan Basin, China & $87.3^{4}$ & 105.0 & 30.8 \\
\hline Beijing, China & 10.8 & 116.2 & 40.1 \\
\hline Tianjin, China & 9.3 & 116.2 & 38.2 \\
\hline Shanghai, China & 12.7 & 121.9 & 30.8 \\
\hline Seoul, Korea & 9.6 & 127.5 & 38.2 \\
\hline Tokyo, Japan & 35.3 & 138.8 & 34.5 \\
\hline Osaka, Japan & 11.3 & 135.0 & 34.5 \\
\hline Hong Kong / PRD, China & $7.2 / 40.1^{5}$ & 114.4 & 23.3 \\
\hline \multicolumn{4}{|l|}{ Southeast Asia } \\
\hline Manila, Philippines & 10.7 & 120.0 & 14.0 \\
\hline Bangkok, Thailand & 6.6 & 101.2 & 14.0 \\
\hline Jakarta, Indonesia & 13.2 & 106.9 & -6.5 \\
\hline \multicolumn{4}{|l|}{ Australia } \\
\hline Sydney, Australia & 4.4 & 151.9 & -32.6 \\
\hline \multicolumn{4}{|l|}{ North America } \\
\hline Chicago, USA & 8.7 & 271.9 & 42.0 \\
\hline New York, USA & 18.5 & 286.9 & 40.1 \\
\hline Los Angeles, USA & 12.1 & 241.9 & 34.5 \\
\hline Atlanta, USA & 4.9 & 275.6 & 32.6 \\
\hline Mexico City, Mexico & 19.0 & 260.6 & 19.6 \\
\hline \multicolumn{4}{|l|}{ South America } \\
\hline Bogota, Colombia & 7.6 & 285.0 & 4.7 \\
\hline Lima, Peru & 8.2 & 283.1 & -12.1 \\
\hline Rio de Janeiro, Brazil & 11.5 & 316.9 & -21.5 \\
\hline Sao Paulo, Brazil & 18.3 & 313.1 & -23.3 \\
\hline Buenos Aires, Argentina & 13.3 & 301.9 & -34.5 \\
\hline
\end{tabular}

${ }^{1}$ Source (unless otherwise noted): Population Division of the Department of Economic and Social Affairs of the United Nations Secretariat (2004) and World Urbanization Prospects: The 2003 Revision, Web: http://www.unpopulation.org; compilation accessible at http://www. infoplease.com/ipa/A0884418.html.

2 The latitudes and longitudes correspond to the model grid cells in which the tracers are emitted, and do not necessarily correspond exactly to the locations of the represented cities or regions themselves.

${ }^{3}$ Exact population figure not found; lower limit estimate based on the sum of the populations of Milano and Turino.

${ }^{4}$ For a provincial area of $485000 \mathrm{~km}$, covering about $12 \mathrm{~T} 63$ grid cells; from http://en.wikipedia.org/wiki/Sichuan, version from 14:13, 10 July 2007, based on the original source China Statistical Yearbook, 2005, ISBN 7503747382.

5 Approximate population of the Pearl River Delta zone; from http://en.wikipedia.org/wiki/Pearl_River_Delta, version from 07:38, 3 July 2007, based on the 2000 Chinese national census. 
lifetime of aerosols (sulfate, organic and elemental carbon, nitrate, etc.) generally lies between 1 and 10 days, and the global mean lifetimes of several key reactive trace gases fall in this range, including $\mathrm{O}_{3}(\sim 25 \mathrm{~d}), \mathrm{CO}(\sim 60 \mathrm{~d}), \mathrm{NO}_{\mathrm{x}}(\sim 2 \mathrm{~d})$, ethane $(\sim 100 \mathrm{~d})$, propane $(\sim 30 \mathrm{~d})$ and butane $(\sim 3 \mathrm{~d})$. The results of this study are complementary to those in Butler et al. $(2007 a)^{1}$, in which we examine the effect of megacity emissions more specifically on global and regional $\mathrm{O}_{3}$ chemistry, based on the megacity emissions work of Gurjar et al. (2004), Gurjar and Lelieveld (2005), and Butler et al. $(2007 b)^{2}$. The generic tracer approach used here allows these results to also be applicable to other classes of airborne pollutants, such as $\mathrm{Hg}, \mathrm{Pb}$, and persistent organic pollutants (POPs).

The mean geographical distributions of these tracers are compared making use of a set of metrics which helps quantify either the degree of export or the coherent retention of the tracers in the source region. Both horizontal and vertical transport contribute to tracer outflow. Horizontal dispersion in the boundary layer (BL) transports pollutants to other regions, where they can still have direct effects on health, agriculture and visibility. Vertical dispersion, especially by cumulus convection, removes pollutants from the surface layer, and in turn transports them to the free and upper troposphere, where the lifetimes of many trace gases and aerosols are much longer, their climate effects (e.g., influence on cirrus properties and as greenhouse gases) are more significant, and the potential exists for further transport into the stratosphere. It is not clear a priori what the relative quantitative roles of horizontal and vertical transport are, and how this might vary on a regional basis; this is examined here in light of the regional pollution potential metrics.

Several previous studies have also employed global models to examine the outflow, distribution and influence of pollutants on regional, continental and global scales (e.g. Wild and Akimoto, 2001; Stohl et al., 2002; Lawrence et al., 2003a; Kunhikrishnan and Lawrence, 2004; Pfister et al., 2004); a good review of these is provided by Akimoto (2003). In contrast to these studies, which have focused on emissions from various country-scale to continental-scale regions (e.g., Europe), here we focus on individual megacities and other major population centers, represented as large point sources for the tracers. An alternative approach to studying the outflow characteristics from these concentrated sources would be to employ a regional model. Such models allow a more detailed analysis of local meteorology and regional pollutant distribution, and have provided valuable in-

\footnotetext{
${ }^{1}$ Butler, T. M., Lawrence, M. G., Gurjar, B. R., and Lelieveld, J.: The effects of emissions from megacities on global ozone chemistry, Atmos. Chem. Phys. Discuss., in preparation, 2007a.

${ }^{2}$ Butler, T. M., Lawrence, M. G., Gurjar, B. R., van Aardenne, J., Schultz, M., and Lelieveld, J.: The representation of emissions from megacities in global emissions inventories, Atmos. Environ., in review, 2007b.
}

sights through detailed studies of individual cities (e.g. Guttikunda et al., 2005; de Foy et al., 2006). However, the regional model would then need to be set up to simulate several regions around the world in order to address the question posed above and to allow a comparative analysis of the outflow characteristics of the full large set of chosen source locations. We hope this study might be followed up by similar analyses with regional models, and suggest a few points where this may be particularly valuable.

In the following section we provide descriptions of the global model used for the simulations (MATCH), the source locations and tracers, and the metrics considered in this study. Following that, we discuss the qualitative and quantitative dispersion characteristics for the set of tracers, focusing on three particular issues: low-level long-range export, vertical transport to the upper troposphere (UT), and regional exceedances of density thresholds. Our key conclusions are summarized in the final section, along with recommendations for future studies. Beyond the discussion presented here, for interested readers we also provide an electronic supplement with a full set of figures for the individual source locations, on an annual and seasonal mean basis, as well as key tables and figures for the tracers with different lifetimes.

\section{Methods}

\subsection{Model description}

For this analysis we use the global 3-D Model of Atmospheric Transport and Chemistry (MATCH). MATCH is a semi-offline model which has been described and evaluated in detail in Rasch et al. (1997); Mahowald et al. (1997b,a); Lawrence et al. (1999, 2003a); von Kuhlmann et al. (2003); Lang and Lawrence (2005a,b). The model transport and physics parameterizations are mostly based on the CCM3 (Kiehl et al., 1996). MATCH has been used to study a variety of topics, including long range transport of pollution plumes (Lawrence et al., 2003a), and transport by deep convection and its effects on global tropospheric $\mathrm{O}_{3}$ (Lawrence et al., 2003b; Lawrence and Rasch, 2005). Here we are particularly interested in the quality of the simulated tracer transport, especially in pollutant outflow regions. Previous studies have shown this to be generally very good for $\mathrm{CO}, \mathrm{C}_{3} \mathrm{H}_{8}$ and other pollution tracers, with correlation coefficients between simulated and observed values often being in the 0.7-0.9 range, and with the main exception being in regions where the emissions are not well represented, for example, due to the use of climatological biomass burning emissions (Lawrence et al., 2003a; Gros et al., 2003, 2004; Salisbury et al., 2003).

The simulations discussed here are driven by meteorological data from the NCEP/NCAR reanalysis project (Kalnay et al., 1996) at a horizontal resolution of T63 $(96 \times 192$ grid points, or about $1.9^{\circ}$ ). There are 28 vertical sigma levels 
Table 2. The elevations above sea level along with the geopotential altitudes from the model simulation for the high-altitude MPCs.

\begin{tabular}{lrr}
\hline City & Actual $^{1}(\mathrm{~m})$ & Model $^{(\mathrm{m})}$ \\
\hline Bogota, Colombia & 2660 & 1571 \\
Mexico City, Mexico & 2259 & 1815 \\
Johannesburg, South Africa & 1753 & 1724 \\
Teheran, Iran & 1219 & 1991 \\
Sao Paulo, Brazil & 760 & 610 \\
Lima, Peru & 128 & 1668 \\
\hline
\end{tabular}

1 Sources: http://www.hargravesfluidics.com/alt_city.php and http: //en.wikipedia.org

from the surface to about $2 \mathrm{hPa}$; for a reference surface pressure of $1000 \mathrm{hPa}$, the midpoint pressures of the levels below $100 \mathrm{hPa}$ are: 995.0, 982.1, 964.4, 942.5, 915.9, 883.8, 845.8, 801.4, 750.8, 694.3, 632.9, 568.1, 501.7, 435.7, 372, 312.5, $258.2,210.1,168.2,132.6$, and $102.8 \mathrm{hPa}$. The surface layer is normally $80-90 \mathrm{~m}$ thick. The setup is similar to that used in Lawrence et al. (1999) and von Kuhlmann et al. (2003), but focusing only on artificial tracers, and including the new plume ensemble tracer transport representation for deep convection from Lawrence and Rasch (2005). The model is run in a "semi-offline" mode, relying only on a limited set of input data fields, which are: surface pressure, geopotential, temperature, horizontal winds, surface latent and sensible heat fluxes, and zonal and meridional wind stresses. These are interpolated in time to the model time step of $30 \mathrm{~min}$, and used to diagnose online the transport by advection, vertical diffusion, and deep convection, as well as the tropospheric hydrological cycle (water vapor transport, cloud condensate formation and precipitation). All runs analyzed here are for the year 1995, which was chosen as a "neutral" year with regards to the ENSO. For the 1 and 10-day lifetime tracers, one month (December, 1994) is used as a spinup, while for the 100-day lifetime tracers a 1-year spinup (1994) is used.

\subsection{Tracer emissions and decay}

A set of tracers is emitted at the same rate, $1 \mathrm{~kg} / \mathrm{s}$, into the model surface layer at each major population center source location. The emission is per grid cell, so that the same mass of each tracer is emitted over time, regardless of the source grid cell location or size (for the larger major population centers, like the Szechuan Basin, the emission is only into the single grid cell with the coordinates given in Table 1). Following emission, the tracers are transported with the model parameterizations, and a uniform global decay rate is applied to the tracer mixing ratios each time step. Three characteristic decay rates have been chosen: $1 \mathrm{~d}, 10 \mathrm{~d}$, and $100 \mathrm{~d}$, which correspond to the main range of tracers of interest in urban and regional air pollution, as discussed in the introduction. Wet and dry deposition processes are not included for the tracers. The tracer mixing ratios are archived on a monthly mean basis.

\subsection{Tracer source locations}

Table 1 lists the major population centers ("MPCs") chosen for the simulations, along with their approximate populations and the corresponding closest model grid cell latitudes and longitudes at the chosen resolution. Thirty of these MPCs correspond to the worldwide most populated cities in 2000, with populations ranging from about 7 million (Hong Kong, Teheran and Chicago) to more than 20 million (Mexico City and Tokyo). Six additional major population centers have also been included, helping to improve the global coverage: Po Valley, Italy; Johannesburg, South Africa; Szechuan Basin, China; Sydney, Australia; Atlanta, USA; and Bogota, Colombia. Some of the megacities chosen are to an extent representative of even greater metropolitan areas, such as the Pearl River Delta (PRD) adjacent to Hong Kong, and the Boston-New York-Washington (BosNYWash) extended metropolis surrounding New York City. Note that we actually included about ten other source locations in our simulations to further improve the geographical representation, but determined that they did not provide any substantial additional information beyond the conclusions that are drawn based on the selected set; in a few cases, however, some of these additional tracer results will be referred to below to emphasize certain points.

The geographical distribution of the locations of the chosen MPCs can be seen in Fig. 1, which is discussed in more detail in Sect. 3. Considering first the "proper" megacities, most are in the Northern Hemisphere, and the greatest concentration of megacities is clearly in Asia, though there is a relatively good global coverage. The coverage is improved considerably with the inclusion of the additional MPCs mentioned above, especially Johannesburg and Sydney. The majority of the MPCs are either directly coastal, or within about $100 \mathrm{~km}$ of a coast (mostly oceanic, though in some cases like the Po Valley, Teheran and Chicago, also near large seas and lakes). Because of this, many of the MPCs are either nearly at sea level or are within a few hundred meters altitude. However, there are several exceptions to this, with a few being at very high elevations, as listed in Table 2. In general, the model at the resolution employed (T63) is able to capture the characteristic high elevation of these cities, especially for plateaus like the highveld around Johannesburg, although it often tends to underestimate the altitude due to the smearing out of detailed orographic features in the model grid cells. One of the main exceptions to this is Lima, for which the geopotential altitude of the corresponding model grid is much higher than the actual altitude of the city. This is due to its close proximity to the Andes mountain range, which is partially included in the grid cell including Lima. A few other MPCs are also affected by this interpolation of orography, especially for mountains near 
(a)

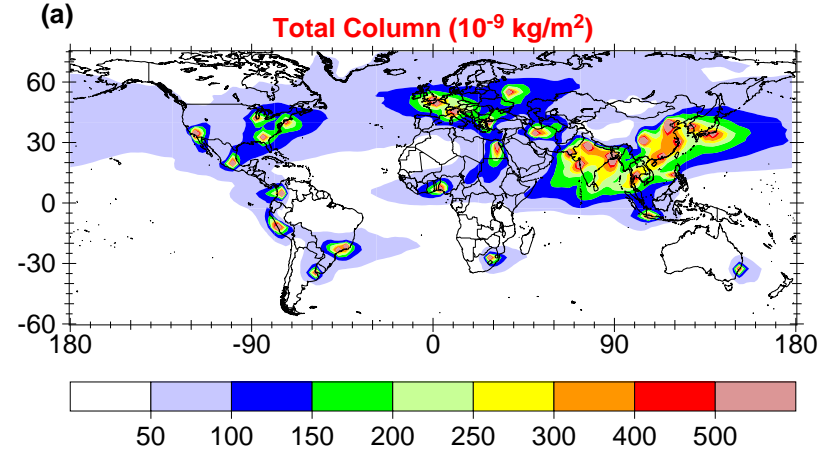

(b)

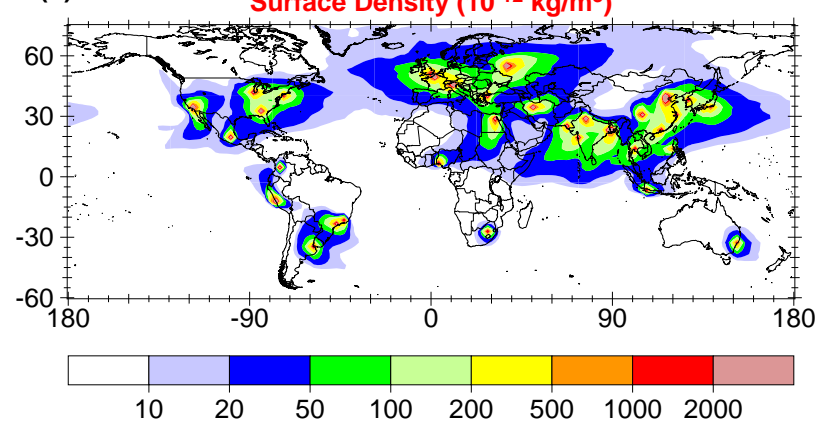

(c) Upper Tropospheric Column, above $5 \mathrm{~km}\left(10^{-9} \mathrm{~kg} / \mathrm{m}^{2}\right)$

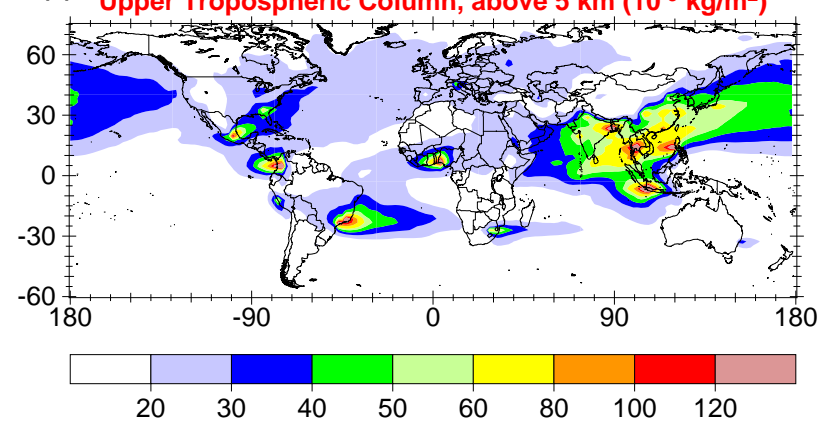

Fig. 1. The annual mean sum of all $\tau=10 \mathrm{~d}$ MPC tracers for (a) the total column mass density $\left(10^{-9} \mathrm{~kg} / \mathrm{m}^{2}\right)$, (b) the model surface layer density $\left(10^{-12} \mathrm{~kg} / \mathrm{m}^{3}\right)$, and (c) the column above $5 \mathrm{~km}$ $\left(10^{-9} \mathrm{~kg} / \mathrm{m}^{2}\right)$.

coasts or valleys, though not as severely as Lima; the main MPCs affected are the Po Valley (modeled altitude: $942 \mathrm{~m}$; actual elevation: $\sim 100-200 \mathrm{~m})$, the Szechuan Basin (764 m vs. $\sim 200-500 \mathrm{~m}$ ), Beijing (740 m vs. $\sim 40 \mathrm{~m}$ ), and Rio de Janeiro ( $600 \mathrm{~m}$ vs. $\sim 10 \mathrm{~m}$; note the proximity to Sao Paulo, listed in Table 2, which is at a much higher altitude than Rio de Janeiro). For these MPCs, it can be expected that the results presented here will be biased towards more long-range transport in the free troposphere and less retention at low altitudes. The deviations in modeled geopotential altitude for the remaining MPCs, at elevations near sea level, are generally small.
Table 3. Brief descriptions of the metrics used in this study.

\begin{tabular}{ll}
\hline Symbol & Metric \\
\hline$E L R_{\text {col }}$ & $\begin{array}{l}\text { Fraction of total tracer mass which is beyond } \\
1000 \mathrm{~km} \text { away from the source point (at any al- } \\
\text { titude) }\end{array}$ \\
$E L R_{1 \mathrm{~km}}$ & $\begin{array}{l}\text { Fraction of total tracer mass which is beyond } \\
1000 \mathrm{~km} \text { away from the source point, and re- } \\
\text { mains below } 1 \mathrm{~km} \text { altitude }\end{array}$ \\
$E_{\mathrm{UT}}$ & $\begin{array}{l}\text { Fraction of total tracer mass which is above } \\
5 \mathrm{~km} \text { altitude (at any horizontal location) }\end{array}$ \\
& $\begin{array}{l}\text { Total surface area (in } 10^{6} \mathrm{~km}^{2} \text { ) of the model } \\
A_{x}\end{array}$ \\
& $\begin{array}{l}\text { grid cells with a tracer density exceeding } \\
x \mathrm{ng} / \mathrm{m}^{3}, \text { where } x=1,10, \text { and } 100 \mathrm{ng} / \mathrm{m}^{3}\end{array}$ \\
\hline
\end{tabular}

\subsection{Metrics}

The metrics which are employed to examine the tracer distributions are focused on addressing two main questions:

- How much of the tracer mass is exported beyond a given distance (horizontal and/or vertical)?

- How large is the geographical area surrounding the source location with a substantial pollution buildup?

We have examined a wide variety of metrics for quantifying the dispersion of these tracers. In this paper, we focus on a subset of these, summarized in Table 3, which illustrate the main findings regarding global tracer dispersion characteristics. The metrics are computed for both monthly and annual mean output, and the ranks of the MPCs are discussed for each metric.

The first basic type of metric is the mass which is exported to a chosen minimum distance away from the city, in the horizontal and/or vertical. For the pollutant export over long ranges ("ELR") in the horizontal, we focus on the low-level export in terms of the fraction of total tracer mass in the lowest $1 \mathrm{~km}$ of the model which is transported to more than $1000 \mathrm{~km}$ away from the source location, denoted as $E L R_{1 \mathrm{~km}}$. We have also considered other distance thresholds (e.g., $500 \mathrm{~km}, 2000 \mathrm{~km}$ ), but find the same qualitative results to hold as for $1000 \mathrm{~km}$. This scale, which represents a rough boundary between regional and continental scale pollution, should be appropriate for studies with the model at T63 resolution, since a circle with a radius of $1000 \mathrm{~km}$ is represented by $\sim 100$ model grid cells. In addition, we briefly note the main results for the overall long-range horizontal export (to beyond $1000 \mathrm{~km}$ ) at any altitude within the column, $E L R_{\text {col }}$. Vertical export to the upper troposphere (UT) is discussed in terms of the fractional mass of each tracer which resides above $5 \mathrm{~km}$, at any horizontal distance from the source $\left(E_{\mathrm{UT}}\right)$.

To compute $E L R_{\mathrm{col}}$ and $E L R_{1 \mathrm{~km}}$, it is necessary to determine the longitude/latitude coordinates of circles of 
the desired radii surrounding each chosen source point. We approximate such circles by determining the locations of a set of equidistant points around each source point. The transformation from distances in meters to the graticule (latitudelongitude grid) is based on the radii of the WGS84 ellipsoid (National Imagery and Mapping Agency, http://earthinfo.nga.mil/GandG/publications/tr8350.2/wgs84fin.pdf,

2000). Only the appropriate fraction of the tracer masses are taken for the set of grid cells which are on the boundaries of the circles (i.e., partly inside and outside the circles); for these border grid cells, the assumption is made that they are rectangular, and the fraction inside or outside the circle is calculated as an area weighted factor using the gridcell edges and the spline formed by the equidistant points (the error due to this assumption is $<1 \%$, which was tested by summing up the areas enclosed by the circles using this approach versus the actual analytically computed geometric surface area of the circles).

A completely different type of metric which we consider is the geographical area (including the source grid cell), which we denote as $A_{x}$, over which the tracer density in the surface layer exceeds a chosen threshold $x\left(\right.$ in $\left.\mathrm{ng} / \mathrm{m}^{3}\right)$. In Sect. 3.3 we consider $A_{1}, A_{10}$, and $A_{100}$ (threshold densities 1,10 , and $100 \mathrm{ng} / \mathrm{m}^{3}$, respectively), mostly focusing on the results for $A_{10}$. Note that we choose to work in density here, since this is more commonly applied in air pollution studies (the conversion to mass mixing ratio at the surface is straightforward, since surface air has a density of close to $1 \mathrm{~kg} / \mathrm{m}^{3}$ ). This metric is similar in principle to the "megacity footprint" defined by Guttikunda et al. (2005), in which they consider the area in which the emissions from a megacity contribute to $10 \%$ or more of the monthly mean ambient concentrations of real pollutants below $1 \mathrm{~km}$ altitude. The metrics $A_{1}, A_{10}$, and $A_{100}$ indicate the coherence of the outflow plumes, that is, the extent to which they remain as concentrated polluted regions (including, surrounding and downwind of the MPC) versus being rapidly dispersed and diluted to lower densities away from the source. We expect this metric to generally be complementary to $E L R_{1 \mathrm{~km}}$ and $E_{\mathrm{UT}}$, since they instead represent the transport and thus dilution of the tracer over large horizontal or vertical distances. The relationship between the metrics in terms of the results from the simulations is discussed in Sect. 3.4.

\section{Qualitative and quantitative dispersion characteris- tics}

Figure 1 shows the annual mean column-integrated density summed over all of the $\tau=10 \mathrm{~d}$ tracers from the source locations listed in Table 1, along with the surface density and the upper tropospheric column-integrated density. The global outflow figures for the $\tau=1 \mathrm{~d}$ and $\tau=100 \mathrm{~d}$ tracers (see the electronic supplement http://www.atmos-chem-phys.net/ 7/3969/2007/acp-7-3969-2007-supplement.pdf) are qualita- tively similar to the $\tau=10 \mathrm{~d}$ tracers, though with less ( $\tau=1 \mathrm{~d}$ ) or more $(\tau=100 \mathrm{~d})$ effective dispersion, respectively, as could be anticipated from the different lifetimes. In the following sections, we discuss the results based on the metrics described in Table 3. In each section, we focus first on the main general results for the $\tau=10 \mathrm{~d}$ tracers, then discuss differences for the $\tau=1 \mathrm{~d}$ and $\tau=100 \mathrm{~d}$ tracers, along with more specific points for individual MPCs.

\subsection{Low-level long-range export}

\subsubsection{General results}

The outflow in the model surface layer (Fig. 1b) can be compared to the column densities (Fig. 1a), showing that the retention of pollutants near the surface tends to be stronger in the mid- and high-latitudes than in the tropics. For most sources, the surface flow pattern dominates the total (column) outflow; the main exceptions to this are in the tropics, particularly in South America, where much of the mass is lofted to the UT, and the UT flow direction is different than near the surface.

The values of $E L R_{1 \mathrm{~km}}$ for the $\tau=10 \mathrm{~d}$ tracers are listed in Table 4. The table gives the annual mean and seasonal variability (standard deviation of the 12 monthly means) for each MPC. Seasonally, the low-level long-range export is almost uniformly largest during the winter. Overall, the annual mean $E L R_{1} \mathrm{~km}$ varies by more than an order of magnitude, from $34 \%$ for Moscow to $3.2 \%$ for Jakarta, with an average value of $14.1 \%$, which makes this a good metric for distinguishing the MPCs in different regions. This is in contrast to the metric $E L R_{\mathrm{col}}$, which only ranges from $62 \%$ to $84 \%$ (not listed in Table 4), implying that it is important to add a vertical component to the long range export, as is done with $E L R_{1 \mathrm{~km}}$, in order to distinguish the MPCs well.

The greatest long-range export of pollutant mass near the surface is for the seven source locations in the region of approximately $0^{\circ}-50^{\circ} \mathrm{E}$ and $25^{\circ}-55^{\circ} \mathrm{N}$ (Europe, western Asia, and northern Africa), with an average $E L R_{1} \mathrm{~km}$ of $23.4 \%$ and an average rank of 5.1. These are followed by the NE Chinese cities (mean $E L R_{1 \mathrm{~km}}=18.4 \%$, mean rank of 9.3), and by the two northeastern USA source locations (mean $E L R_{1 \mathrm{~km}}=17.7 \%$, mean rank of 11.5). At the other end, the lowest values are generally computed for MPCs at high elevations (Table 2), for which a reduced $E L R_{1 \mathrm{~km}}$ from horizontal transport to surrounding, lower-elevation regions can be expected, and for MPCs where there is strong convective activity, removing pollutants from the BL before they can be transported far downwind. Examples include cities in Southeast and East Asian (Manila, Bangkok, Jakarta, and the Szechuan Basin), North and South America (Mexico City, Bogota, Sao Paulo, and Rio de Janeiro), and African (Lagos and Johannesburg), with a mean for these of $E L R_{1 \mathrm{~km}}=5.6 \%$ and a mean rank of 31.5 . 
Table 4. Annual mean regional pollution potentials of the selected MPC source locations for the $\tau=10 \mathrm{~d}$ tracers, with \pm standard deviations of the monthly means for the values, and minimum and maximum monthly values (in parenthesis) for the ranks.

\begin{tabular}{|c|c|c|c|c|c|c|c|c|}
\hline \multirow[b]{2}{*}{ City } & \multicolumn{2}{|c|}{$E L R_{1 \mathrm{~km}}$} & \multicolumn{3}{|c|}{$E_{\mathrm{UT}}$} & \multicolumn{3}{|c|}{$A_{10}$} \\
\hline & $\%$ & Rank & $\%$ & & Rank & $\times 10^{6} \mathrm{~km}^{2}$ & & Rank \\
\hline \multicolumn{9}{|l|}{ Eurasia } \\
\hline London, England & $26.0 \pm 2.5$ & $2(1-4)$ & $11.7 \pm 2.8$ & 35 & $(31-36)$ & $6.7 \pm 1.4$ & & $(1-15)$ \\
\hline Paris, France & $24.8 \pm 4.1$ & $3(1-9)$ & $12.7 \pm 4.8$ & 34 & $(31-35)$ & $6.7 \pm 1.2$ & 3 & $(1-14)$ \\
\hline Moscow, Russia & $34.2 \pm 13.5$ & $1(1-25)$ & $9.6 \pm 13.1$ & 36 & $(14-36)$ & $11.1 \pm 4.9$ & 1 & $(1-25)$ \\
\hline Po Valley, Italy & $18.5 \pm 7.4$ & $10(2-19)$ & $16.5 \pm 13.2$ & 30 & $(18-35)$ & $5.0 \pm 2.1$ & 13 & $(7-33)$ \\
\hline Istanbul, Turkey & $21.7 \pm 4.9$ & $4(4-11)$ & $14.9 \pm 6.7$ & 32 & $(27-34)$ & $5.7 \pm 1.1$ & 11 & $(4-19)$ \\
\hline Teheran, Iran & $17.2 \pm 7.5$ & $11(7-24)$ & $15.7 \pm 9.4$ & 31 & $(14-35)$ & $4.3 \pm 1.9$ & 18 & $(9-29)$ \\
\hline \multicolumn{9}{|l|}{ Africa } \\
\hline Cairo, Egypt & $21.6 \pm 6.8$ & $5(3-15)$ & $14.5 \pm 4.4$ & 33 & $(25-34)$ & $6.1 \pm 2.1$ & 5 & $(5-16)$ \\
\hline Lagos, Nigeria & $6.0 \pm 0.9$ & $29(23-30)$ & $44.5 \pm 8.8$ & 8 & $(7-14)$ & $0.9 \pm 0.3$ & 35 & $(29-35)$ \\
\hline Johannesburg, South Africa & $6.5 \pm 4.3$ & $28(8-33)$ & $42.4 \pm 13.7$ & 9 & $(4-34)$ & $1.2 \pm 1.3$ & 34 & $(9-36)$ \\
\hline \multicolumn{9}{|l|}{ Southern Asia } \\
\hline Karachi, Pakistan & $17.1 \pm 7.2$ & $12(7-25)$ & $22.5 \pm 11.3$ & 28 & $(17-33)$ & $5.7 \pm 2.4$ & 10 & $(4-27)$ \\
\hline Mumbai, India & $14.5 \pm 5.2$ & $18(13-24)$ & $27.6 \pm 13.2$ & 20 & $(12-30)$ & $4.7 \pm 1.7$ & 15 & $(14-24)$ \\
\hline Delhi, India & $18.9 \pm 10.6$ & $8(2-35)$ & $24.9 \pm 18.3$ & 25 & $(7-32)$ & $6.6 \pm 3.3$ & 4 & $(2-32)$ \\
\hline Kolkata, India & $13.5 \pm 8.0$ & $19(11-35)$ & $36.8 \pm 20.6$ & 13 & $(3-22)$ & $4.8 \pm 2.6$ & 14 & $(8-34)$ \\
\hline Dhaka, Bangladesh & $13.3 \pm 8.1$ & $20(12-34)$ & $39.2 \pm 19.6$ & 12 & $(2-19)$ & $4.5 \pm 2.3$ & 16 & $(12-31)$ \\
\hline \multicolumn{9}{|l|}{ Eastern Asia } \\
\hline Szechuan Basin, China & $5.8 \pm 2.6$ & $31(28-36)$ & $39.4 \pm 18.1$ & 10 & $(2-17)$ & $1.3 \pm 0.3$ & 31 & $(28-33)$ \\
\hline Beijing, China & $19.8 \pm 7.3$ & $6(6-24)$ & $24.3 \pm 10.7$ & 26 & $(17-30)$ & $5.9 \pm 2.2$ & 8 & $(3-24)$ \\
\hline Tianjin, China & $18.5 \pm 7.1$ & $9(8-26)$ & $25.6 \pm 13.4$ & 24 & $(12-28)$ & $6.1 \pm 2.5$ & 6 & $(3-27)$ \\
\hline Shanghai, China & $16.8 \pm 6.3$ & $13(10-22)$ & $32.7 \pm 14.7$ & 18 & $(9-24)$ & $6.0 \pm 1.9$ & 7 & $(4-16)$ \\
\hline Seoul, Korea & $16.7 \pm 3.6$ & $15(2-18)$ & $27.1 \pm 6.6$ & 21 & $(17-34)$ & $4.2 \pm 1.0$ & 20 & $(2-23)$ \\
\hline Tokyo, Japan & $11.5 \pm 2.6$ & $24(11-24)$ & $36.5 \pm 9.9$ & 14 & $(12-22)$ & $2.2 \pm 0.8$ & 26 & $(11-27)$ \\
\hline Osaka, Japan & $13.2 \pm 2.0$ & $21(8-22)$ & $33.9 \pm 6.8$ & 17 & $(13-28)$ & $3.2 \pm 0.7$ & 23 & $(8-23)$ \\
\hline Hong Kong / PRD, China & $12.9 \pm 6.5$ & $22(19-34)$ & $39.3 \pm 19.3$ & 11 & $(3-20)$ & $4.5 \pm 1.9$ & 17 & $(15-31)$ \\
\hline \multicolumn{9}{|l|}{ Southeast Asia } \\
\hline Manila, Philippines & $5.8 \pm 3.7$ & $32(22-34)$ & $62.2 \pm 12.9$ & 2 & $(2-10)$ & $1.9 \pm 1.2$ & 29 & $(17-31)$ \\
\hline Bangkok, Thailand & $6.6 \pm 3.7$ & $27(25-36)$ & $54.8 \pm 20.0$ & 4 & $(1-12)$ & $2.0 \pm 1.0$ & 28 & $(25-36)$ \\
\hline Jakarta, Indonesia & $3.2 \pm 0.9$ & $36(23-36)$ & $66.7 \pm 5.6$ & 1 & $(1-11)$ & $1.3 \pm 0.3$ & 32 & $(25-33)$ \\
\hline \multicolumn{9}{|l|}{ Australia } \\
\hline Sydney, Australia & $11.4 \pm 4.0$ & $25(4-27)$ & $34.5 \pm 6.3$ & 16 & $(8-29)$ & $2.5 \pm 0.9$ & 25 & $(6-28)$ \\
\hline \multicolumn{9}{|l|}{ North America } \\
\hline Chicago, USA & $19.3 \pm 6.8$ & $7(5-19)$ & $23.9 \pm 13.0$ & 27 & $(13-30)$ & $5.8 \pm 2.0$ & 9 & $(2-19)$ \\
\hline New York, USA & $16.0 \pm 2.3$ & $16(5-20)$ & $26.4 \pm 6.4$ & 23 & $(21-32)$ & $4.1 \pm 0.7$ & 21 & $(3-21)$ \\
\hline Los Angeles, USA & $16.7 \pm 5.9$ & $14(4-20)$ & $22.0 \pm 4.6$ & 29 & $(16-29)$ & $5.3 \pm 1.6$ & 12 & $(4-19)$ \\
\hline Atlanta, USA & $12.2 \pm 4.9$ & $23(19-31)$ & $35.5 \pm 15.7$ & 15 & $(7-21)$ & $4.2 \pm 1.6$ & 19 & $(13-30)$ \\
\hline Mexico City, Mexico & $5.5 \pm 1.2$ & $33(27-34)$ & $45.6 \pm 5.3$ & 7 & $(5-14)$ & $1.2 \pm 0.3$ & 33 & $(30-35)$ \\
\hline \multicolumn{9}{|l|}{ South America } \\
\hline Bogota, Colombia & $5.3 \pm 1.8$ & $35(26-35)$ & $50.4 \pm 8.8$ & 6 & $(5-16)$ & $0.4 \pm 0.2$ & 36 & $(35-36)$ \\
\hline Lima, Peru & $10.9 \pm 5.7$ & $26(1-31)$ & $31.2 \pm 10.0$ & 19 & $(5-35)$ & $3.0 \pm 1.2$ & 24 & $(4-29)$ \\
\hline Rio de Janeiro, Brazil & $6.0 \pm 3.9$ & $30(12-35)$ & $54.4 \pm 16.6$ & 5 & $(2-26)$ & $1.8 \pm 0.9$ & 30 & $(9-33)$ \\
\hline Sao Paulo, Brazil & $5.4 \pm 3.6$ & $34(14-36)$ & $55.3 \pm 15.6$ & 3 & $(2-24)$ & $2.0 \pm 0.9$ & 27 & $(11-31)$ \\
\hline Buenos Aires, Argentina & $14.7 \pm 3.9$ & $17(3-25)$ & $26.5 \pm 5.7$ & 22 & $(10-36)$ & $4.1 \pm 1.5$ & 22 & $(2-24)$ \\
\hline
\end{tabular}



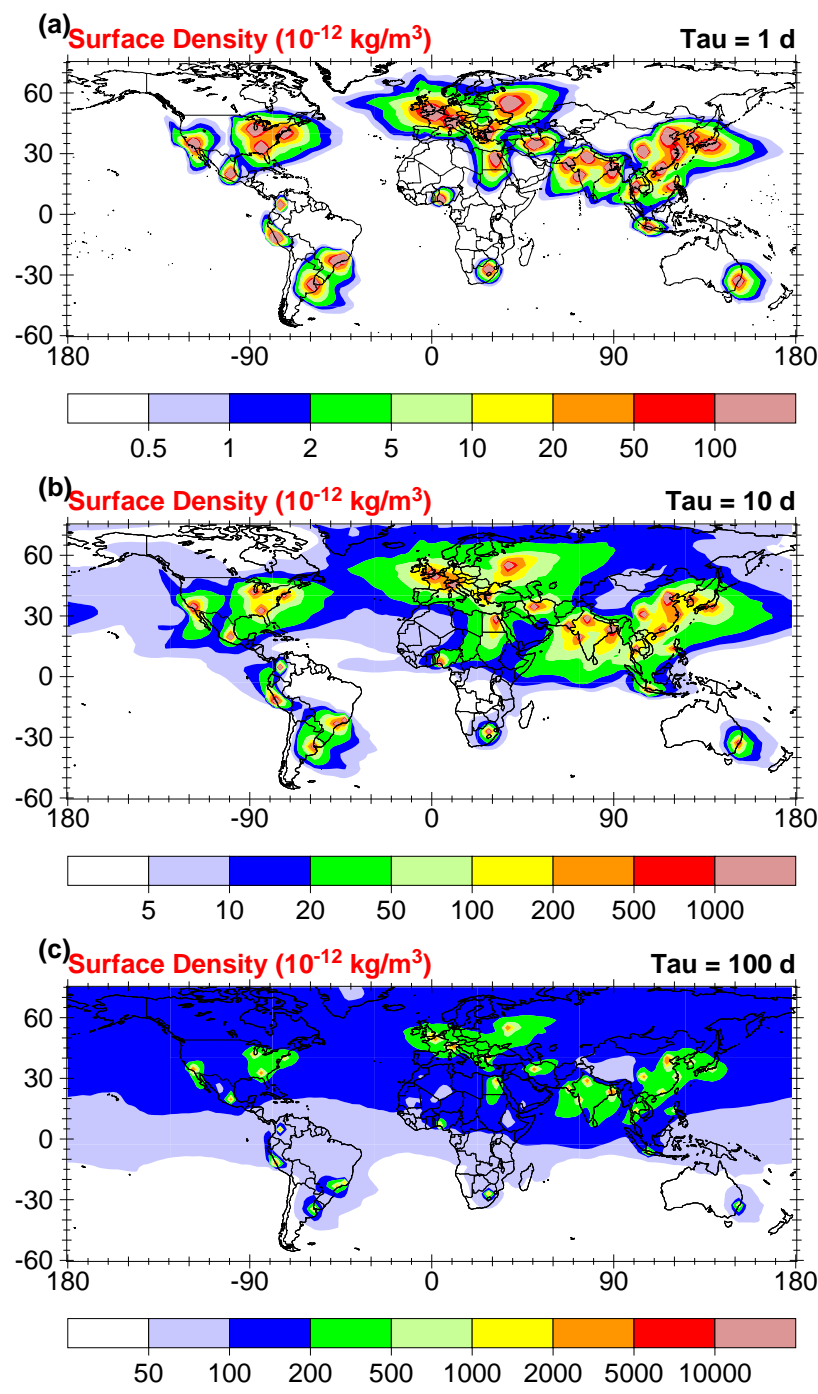

Fig. 2. The annual mean sum of the surface layer densities $\left(10^{-12} \mathrm{~kg} / \mathrm{m}^{3}\right)$ of all of the MPC tracers for (a) $\tau=1 \mathrm{~d}$, (b) $\tau=10 \mathrm{~d}$, and (c) $\tau=100 \mathrm{~d}$; note that the data in panel (b) is the same as in Fig. 1b, except with different contour intervals for better comparison to the other panels.

An important characteristic in terms of the impact of emissions on health and agriculture is how much of the long-range export remains over land, and how much is over the oceans. Since most MPCs are near coasts, the mean $E L R_{1 \mathrm{~km}}$ limited to only land regions is $6.4 \%$, slightly less than half of the mean $E L R_{1 \mathrm{~km}}$ over both surfaces. The values and ranks of the individual tracers for outflow over land versus outflow over both land and sea are well correlated (the correlation between the rankings is $r^{2}=0.88$, with a root mean square (rms) deviation of 3.6). Interestingly, this makes the distinction of MPCs at the extreme ends even stronger: for land-export only, the values of $E L R_{1 \mathrm{~km}}$ range from $28.5 \%$ for Moscow (a land-locked city) down to $0.5 \%$ for Jakarta (on an island).
How do the results change if we make different choices for the outflow depth, minimum outflow distance, and tracer lifetimes? For the outflow depth, we also examined the values for outflow restricted to only the near-surface layer below $100 \mathrm{~m}$. This results in much smaller exported mass fractions, with $E L R_{100 \mathrm{~m}}$ averaging $1.5 \%$, close to the factor of 10 difference in the outflow volumes, but the rankings are nearly identical to those listed in Table $4\left(r^{2}=0.99\right.$, rms $\left.=1.0\right)$. For the dependence on the outflow distances, we can compare the results for outflow beyond either $500 \mathrm{~km}$ or $2000 \mathrm{~km}$, and find again that the rankings compared to outflow beyond $1000 \mathrm{~km}$ do not change significantly $\left(r^{2}=0.98, \mathrm{rms}=1.5\right.$, and $r^{2}=0.91, \mathrm{rms}=3.2$, respectively).

There are more notable differences for the rankings of the $\tau=1 \mathrm{~d}$ and $\tau=100 \mathrm{~d}$ tracers compared to the $\tau=10 \mathrm{~d}$ tracers ( $r^{2}=0.55, \mathrm{rms}=7.5$, and $r^{2}=0.69, \mathrm{rms}=6.1$, respectively). To give a better indication of the overall similarity and differences in the outflow depending on the tracer lifetime, the surface layer outflow for the tracers with the three different lifetimes are plotted in Fig. 2. Since the total global masses of the tracers are proportional to their lifetimes, the contour intervals are also chosen scaled by the lifetimes (e.g., $10 \times$ larger for $\tau=10 \mathrm{~d}$ than for $\tau=1 \mathrm{~d}$ ). While the $\tau=1 \mathrm{~d}$ tracers tend to remain relatively concentrated near their source locations, the $\tau=10 \mathrm{~d}$ tracers disperse readily over continental scales, though they still show substantial peaks in the densities over large regions near their sources. Much of the mass of the $\tau=100 \mathrm{~d}$ tracers, on the other hand, is spread out over the Northern Hemisphere, in the lowest contour interval, and the peak densities at the sources are much less pronounced. More specific differences related to tracer lifetime are discussed in the following section.

\subsubsection{Specific MPC features}

Although there is a general regional classification in the behavior of the tracers from the MPCs, as discussed above, there are also several notable intra-regional differences in $E L R_{1 \mathrm{~km}}$ between MPCs in specific regions. One example is northeastern North America, where frontal disturbances along the east coast of the USA result in tracers being readily lofted by warm conveyor belts (Stohl, 2001), reducing the retention of pollutants near the surface, and thus their potential for long-range low-level export. This results in a less effective export for New York (rank 16) versus nearby Chicago (rank 7), as depicted in Fig. 3 (we also examined additional tracers for Montreal and Toronto, which had $E L R_{1 \mathrm{~km}}$ values very similar to Chicago).

Another notable difference is in southern Asia, where the Asian summer monsoon convection is much stronger towards southern and eastern India and neighboring countries compared to its western side (see Fig. 4). This results in the northern and western cities of Delhi (rank 8) and Karachi (rank 12) being considerably more efficient low-level exporters than Mumbai (18), Kolkata (19) and Dhaka (20). In 

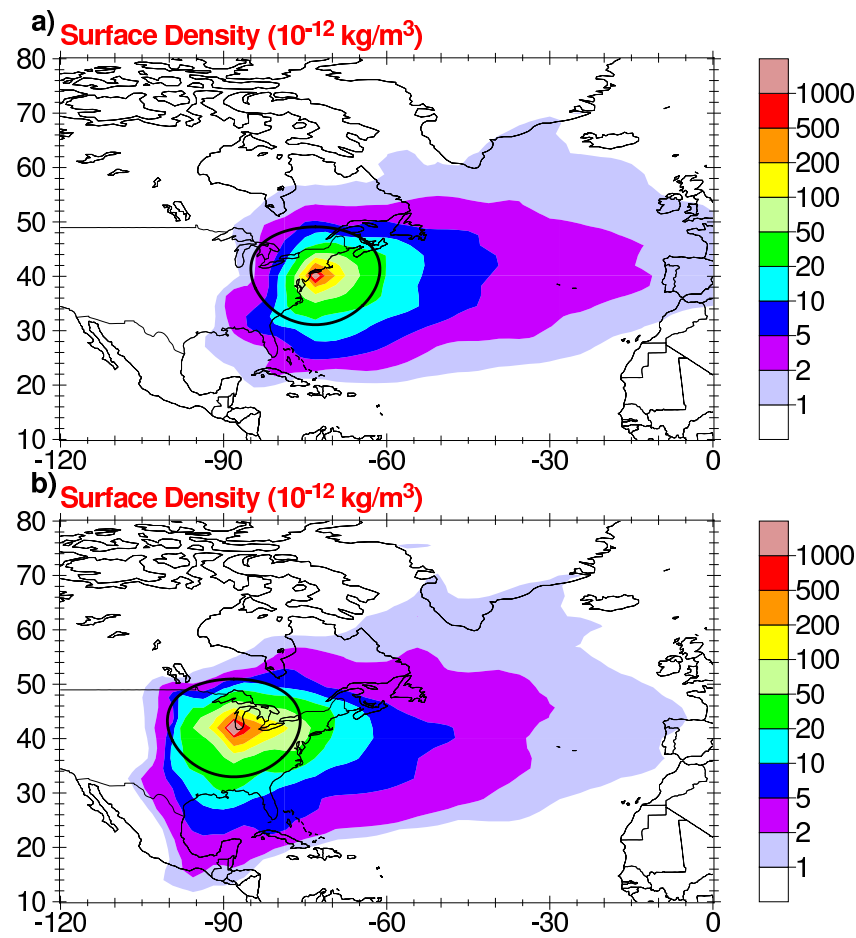

Fig. 3. The annual mean surface layer densities $\left(10^{-12} \mathrm{~kg} / \mathrm{m}^{3}\right)$ of the $\tau=10 \mathrm{~d}$ tracers for (a) New York and (b) Chicago; the black circles depict a $1000 \mathrm{~km}$ radius around the source locations.

Eurasia plus Cairo, where the values and the ranks are all generally high, there is nevertheless nearly a factor of two spread between Teheran and Moscow, and a very good anticorrelation $\left(r^{2}=0.94\right)$ between $E L R_{1} \mathrm{~km}$ and $E_{\mathrm{UT}}$, indicating the importance of convective lifting in determining the export efficiency. South America and southern North America are similarly influenced by intraregional differences in convective activity, where Buenos Aires (17) and Lima (26) retain greater amounts of pollution in the boundary layer and are thus more efficient exporters than the rest of the South American MPCs plus Mexico City (30-35). Likewise, Melbourne, Australia (one of the additional MPCs not selected for Table 4), in the less convective southern region of Australia, has a value of $E L R_{1 \mathrm{~km}}=20.0 \%$, nearly twice that of Sydney $\left(E L R_{1 \mathrm{~km}}=11.4 \%\right)$.

Beyond the differences in vertical lofting due to deep convection and warm conveyor belts, gradients in horizontal winds can also lead to large intraregional differences. An example of this is the Szechuan Basin tracer versus the Hong Kong and Pearl River Delta tracers (and to an extent other eastern Asian MPCs). The mean surface layer winds for January, 1995, for this region are depicted in Fig. 5; other months show a similar contrast between the coastal and inland regions, though less extreme due to the seasonal reversal of the mean wind direction in coastal eastern Asia during the summer monsoon. The contrasting effects of the lo-

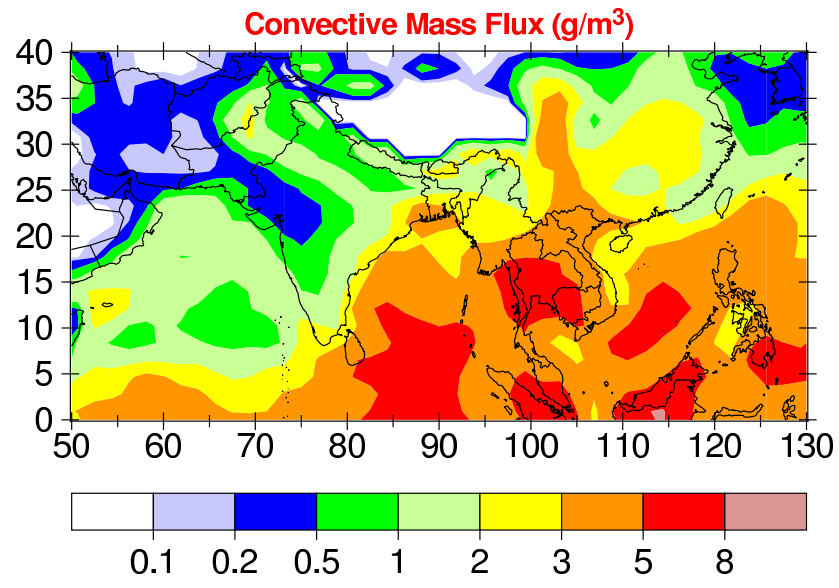

Fig. 4. Annual mean convective mass flux through $500 \mathrm{hPa}$ $\left(\mathrm{g} / \mathrm{m}^{2} / \mathrm{s}\right)$ for the southern Asian region.

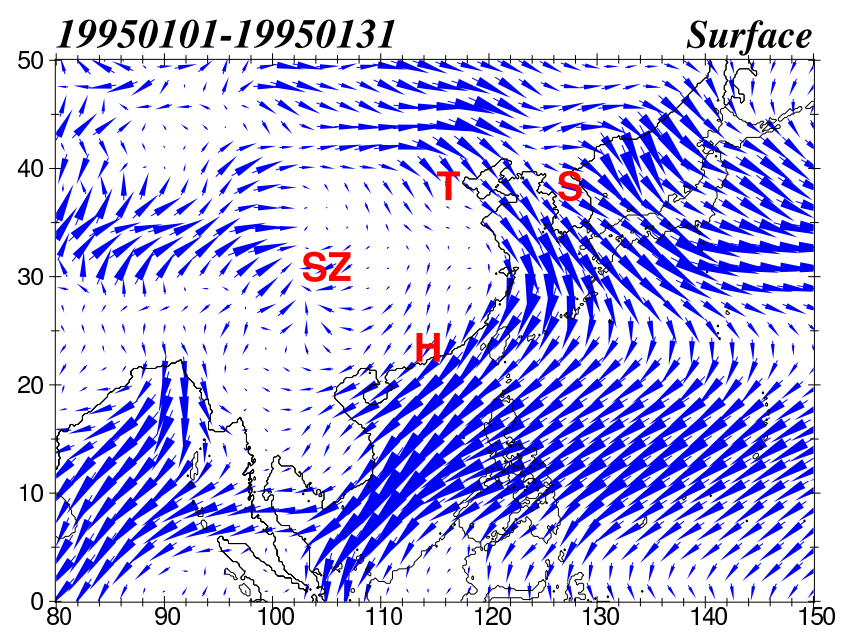

Fig. 5. January mean surface layer winds for the Asian region; the markings indicate the locations of four selected MPCs: SZ Szechuan Basin, H - Hong Kong, T - Tianjin, S - Seoul.

cal circulation on the Szechuan and Hong Kong tracers are shown in Fig. 6. In this case, the differences in the tracers are not due to the transport out of the BL into the UT, which is nearly the same for the two tracers, and strong in both cases, with $E_{\mathrm{UT}}=39.3 \%$ for Hong Kong and $E_{\mathrm{UT}}=39.4 \%$ for the Szechuan Basin tracer. Instead, the tracer mass which is left behind in the BL near the Szechuan Basin tends to remain near its source due to the low-level convergence and recirculation in this region, while in the BL off the coast of Hong Kong the tracer is transported rapidly away by the strong monsoon winds. This results in a value of $E L R_{1 \mathrm{~km}}$ for Hong Kong (12.9\%) which is over twice as large as for the Szechuan Basin (5.8\%).

There is a pronounced seasonality for several MPCs, especially those in southern and eastern Asia, which are affected by the seasonal reversal of the monsoon winds and associated 


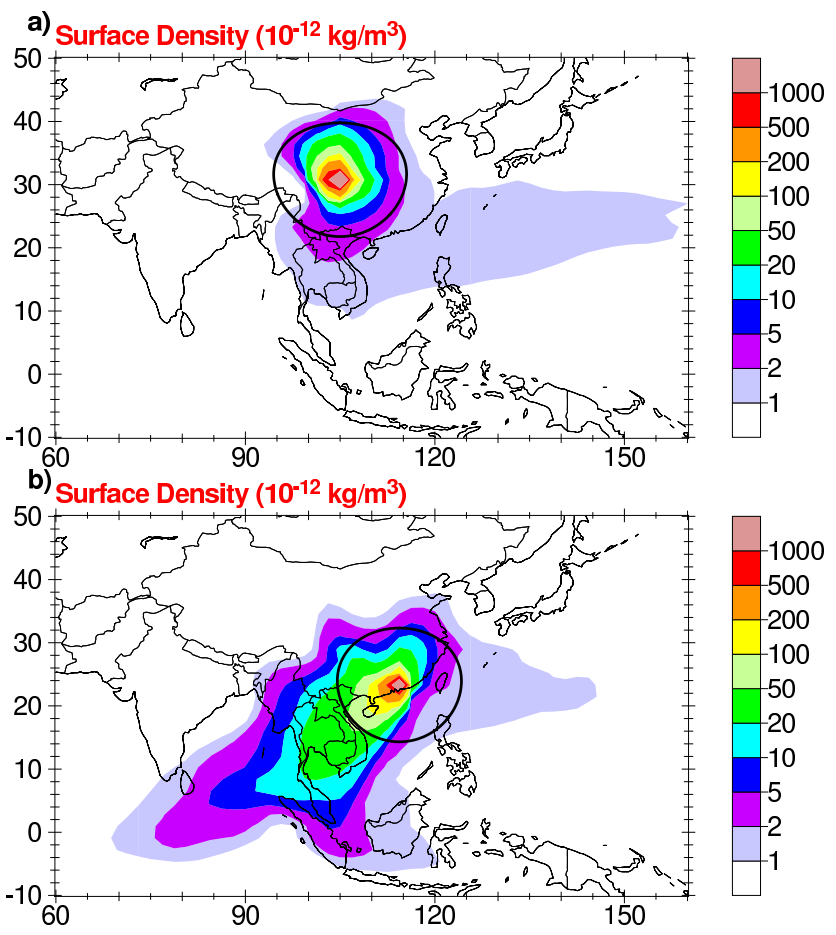

Fig. 6. The annual mean surface layer densities $\left(10^{-12} \mathrm{~kg} / \mathrm{m}^{3}\right)$ of the $\tau=10 \mathrm{~d}$ tracers for (a) the Szechuan Basin and (b) Hong Kong; the black circles depict a $1000 \mathrm{~km}$ radius around the source locations.

changes in deep convection. An example of this is shown in Fig. 7 for Delhi. In December, Delhi has rank 2 for $E L R_{1 \mathrm{~km}}$. In summer, on the other hand, when the intertropical convergence zone (ITCZ) over India causes effective lifting in the monsoon convection, Delhi actually becomes one of the least effective MPCs for low-level pollution export, with a rank of 35. The electronic supplement shows that in most other regions the main geographical dispersion patterns (i.e., outflow directions) tend to be more similar for the MPCs throughout the year, though with a few exceptions. One of the most notable exceptions is Moscow (Fig. 8), which has a strong outflow into the Arctic during the winter and spring, but primarily towards the south during summer. Istanbul, about $15^{\circ} \mathrm{S}$ and $10^{\circ} \mathrm{W}$ of Moscow, has a similar seasonal variability in the geographic patterns of the outflow, but much less outflow reaching the far northern high latitudes. This contribution of Eurasian cities to the so-called "Arctic haze" is similar to what has been noted in previous studies (e.g. Stohl et al., 2002), which have indicated that generally Eurasian pollution should contribute more strongly to the Arctic haze than North American or eastern Asian emissions. Here we confirm this to be the case (see the electronic supplement for the full set of comparative figures), and show that the extent of pollution is substantial for a 10-day lifetime tracer, so that this will apply to important real pollutants like $\mathrm{O}_{3}$ and aerosols. However, we additionally find that the effectiveness per $\mathrm{kg}$ of emissions from Moscow in contributing to the Arctic haze is nearly an order of magnitude greater than that of emissions from Paris or London, and furthermore that the seasonal variability of those two western European cities is much less than that of Moscow.

Finally, there are several interesting cases where the regional meteorology results in tracers of one lifetime having a notably higher rank (i.e., relatively more effective export beyond $1000 \mathrm{~km}$ ) than the other two lifetime tracers from the same MPC. Various processes can contribute to this. One such scenario is when regional export tends to occur first in the $\mathrm{BL}$, or in an overlying residual layer above the marine boundary layer, spreading over several thousand $\mathrm{km}$ at low altitudes before finally encountering a region of strong mixing out of the BL, such as the ITCZ. This results in a relatively much more efficient export for the $\tau=10 \mathrm{~d}$ tracers than for either the $\tau=1 \mathrm{~d}$ or $\tau=100 \mathrm{~d}$, which is found for several cities, including Delhi, Mumbai, Kolkata, Karachi, Beijing, Tianjin, and Cairo. For Delhi, the most extreme case, the annual mean $\tau=10 \mathrm{~d}$ tracer has a rank of 8 , while the $\tau=1 \mathrm{~d}$ and $\tau=100 \mathrm{~d}$ tracers have ranks of 25 and 19 , respectively. For real tracers this implies that those with intermediate lifetimes, especially aerosols, will be most important to focus on in terms of controlling downwind pollution from these cities. The secondary convective entrainment downwind can be seen for several MPCs in the electronic supplement, especially well for Kolkata. This type of coherent outflow over the time-scale of about a week has been studied in various field campaigns, in particular for the Asian winter monsoon during the Indian Ocean Experiment (INDOEX) (Lelieveld et al., 2001; Ramanathan et al., 2002), for which MATCH was shown to accurately simulate the sharp transition between polluted Northern Hemisphere and cleaner Southern Hemisphere surface-layer airmasses at the ITCZ (Lawrence et al., 2003a).

The outflow can also encounter regions of strong lofting out of the BL much sooner after leaving the MPC source locations, which results in a relatively more efficient export for the $\tau=1 \mathrm{~d}$ tracers; Manila and Hong Kong are examples where this occurs (Hong Kong has ranks 5, 22 and 29 for $\tau=1 \mathrm{~d}, 10 \mathrm{~d}$, and $100 \mathrm{~d}$, respectively). At the other extreme, for a few MPCs, including the Po Valley, Buenos Aires, Rio de Janeiro, and Johannesburg, the $\tau=100 \mathrm{~d}$ tracer is much more effectively exported relative to the shorter lifetimes tracers. The Po Valley is the most extreme case for this (with ranks 22,10 and 4 for $\tau=1 \mathrm{~d}, 10 \mathrm{~d}$, and $100 \mathrm{~d}$, respectively). In this case, the shorter-lived tracers are effectively retained in the basin region, and along with the stronger convective lofting, this makes the Po Valley less effective for low-level export than the nearby Eurasian MPCs (Moscow, London, Paris and Istanbul). The longer-lived ( $\tau=100 \mathrm{~d})$ tracers, however, can more readily leave the basin region and be exported into the BL of the surrounding regions, making it more similar to the other Eurasian tracers (Moscow, London, Paris 

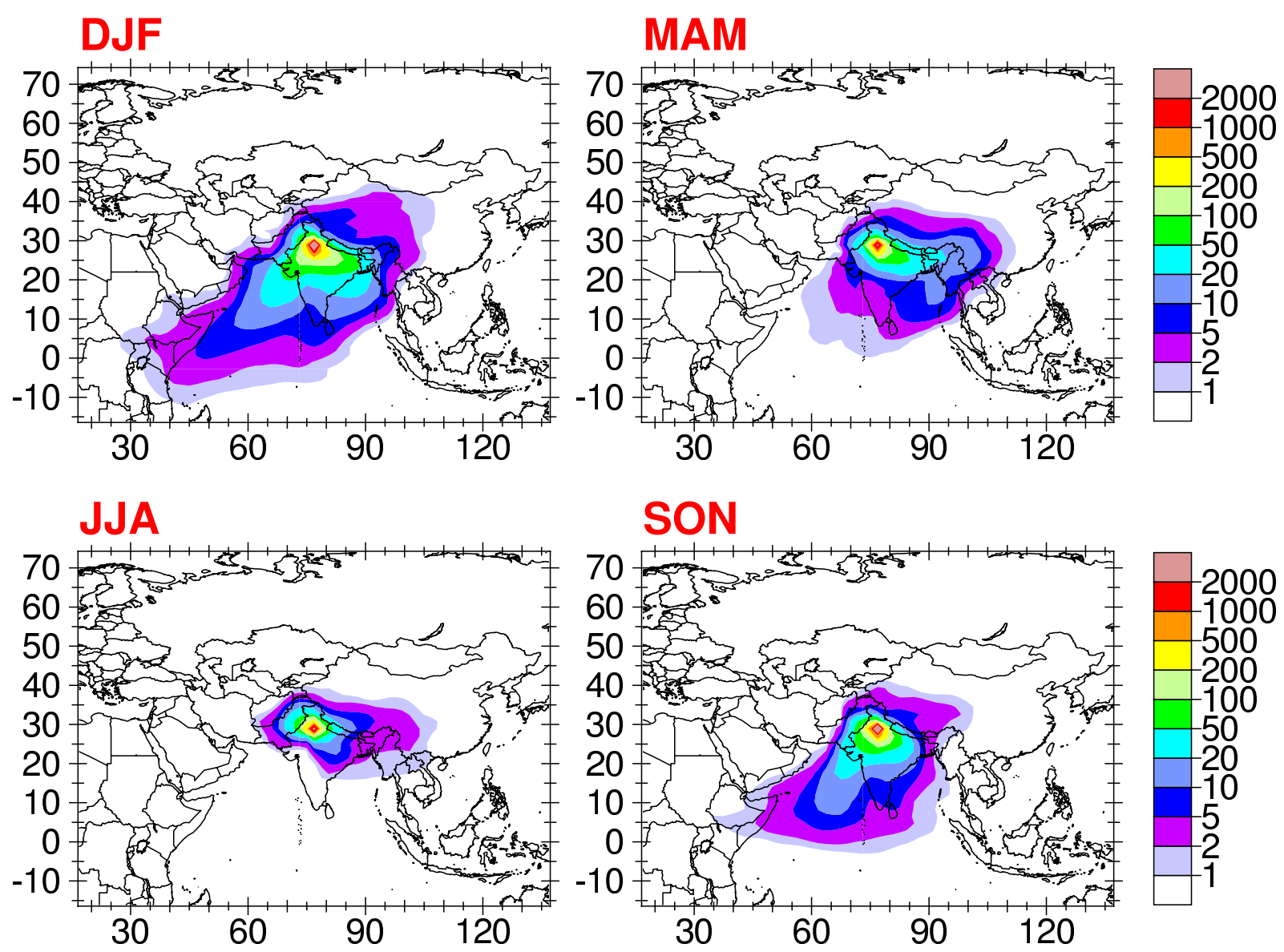

Fig. 7. Seasonal mean surface layer density $\left(10^{-12} \mathrm{~kg} / \mathrm{m}^{3}\right)$ of the $\tau=10 \mathrm{~d}$ tracer for Delhi.

and Istanbul are ranked 1, 2, 3, and 5, respectively, for the $\tau=100 \mathrm{~d}$ tracers).

\subsection{Vertical export to the UT}

\subsubsection{General results}

Transport of certain pollutants from MPCs to the upper troposphere (UT) can be important for various global pollution and climate-related issues: for instance, cirrus clouds in the UT contribute significantly to the global long- and shortwave radiation budget, and may be affected by the upwards transport of pollutants which influence the availability of ice nuclei (e.g., Lohmann, 2002); greenhouse gases such as $\mathrm{O}_{3}$ are more effective in the UT due to the colder temperatures (Lacis et al., 1990); the lifetimes of many gases and aerosols tend to be much longer in the UT than near the surface; and the UT serves as the gateway to the stratosphere, for instance for halogenated gases which can affect the stratospheric $\mathrm{O}_{3}$ layer (WMO, 2002). It is important to recall that the tracers considered here are all insoluble tracers; washout of soluble tracers will substantially reduce their transport to the UT. A rough rule of thumb (Crutzen and Lawrence, 2000) is that for soluble tracers with Henry's Law coefficients of $10^{3}, 10^{4}$, and $10^{5} \mathrm{M} / \mathrm{atm}$, the transport to the UT will be about $15 \%$, $50 \%$ and $85 \%$ as efficient, respectively, as the transport of an insoluble tracer. We plan a more detailed analysis of the fate of soluble tracers in a follow-up study.

Figure $1 \mathrm{c}$ shows the column density above $5 \mathrm{~km}$ for all the $\tau=10 \mathrm{~d}$ MPC tracers, and Table 4 lists the fractional masses of the MPC tracers which reside above $5 \mathrm{~km}\left(E_{\mathrm{UT}}\right)$. The variability in $E_{\mathrm{UT}}$ between the MPCs is substantial, mainly reflecting the global variability in convective activity, with values ranging from $9.6 \%$ for Moscow to $66.7 \%$ for Jakarta. This broad range of values makes $E_{\mathrm{UT}}$ a good metric for separating the MPCs. The variability is greater for the $\tau=1 \mathrm{~d}$ tracer, with $E_{\mathrm{UT}}$ ranging from $0.4-45.7 \%$, while for $\tau=100 \mathrm{~d}$ tracer the range is reduced to $34.0-57.7 \%$. Nevertheless, despite the differences in absolute values, the ranks are generally similar (more so than for $E L R_{1 \mathrm{~km}}$ ), with correlations and deviations between the rankings of the $\tau=1 \mathrm{~d}$ and $\tau=10 \mathrm{~d}$ tracers of $r^{2}=0.88$, rms $=3.6$, and between the $\tau=10 \mathrm{~d}$ and $\tau=100 \mathrm{~d}$ tracers of $r^{2}=0.72, \mathrm{rms}=5.7$. It is worth noting that an even greater spread in the values than computed here would be expected for any trace gases or aerosols with lifetimes that increase with altitude, since this would 

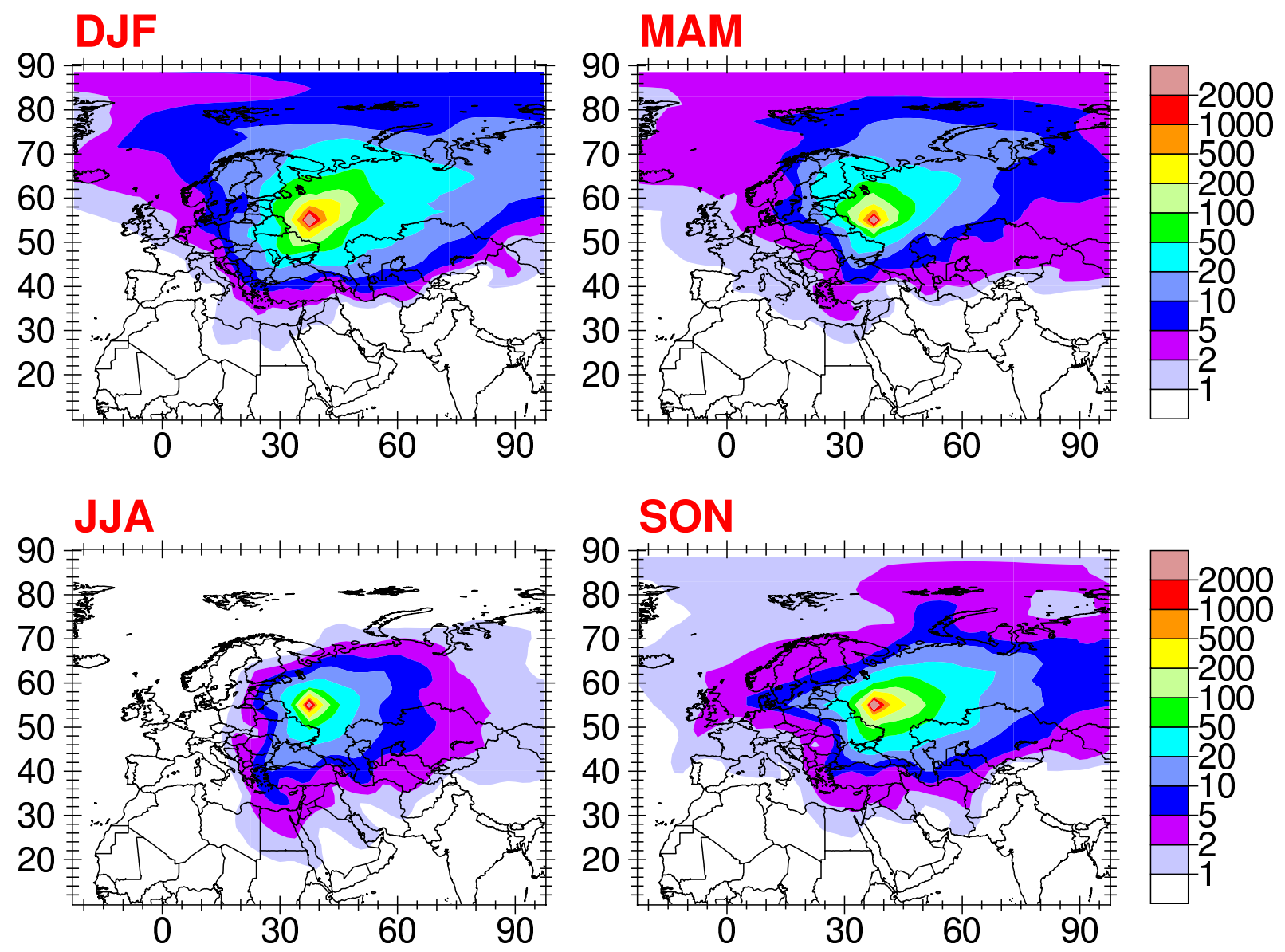

Fig. 8. Seasonal mean surface layer density $\left(10^{-12} \mathrm{~kg} / \mathrm{m}^{3}\right)$ of the $\tau=10 \mathrm{~d}$ tracer for Moscow.

result in a greater global mass for the tracers with more efficient export to the UT (whereas using the current setup provides a lower limit to the variability, since all tracers of a given lifetime, e.g., $\tau=10 \mathrm{~d}$, have the same global total mass).

The strongest export to the UT occurs for the tropical MPCs. A relatively strong anti-correlation is computed between $E_{\mathrm{UT}}$ and the absolute latitude of the MPCs $\left(r^{2}=0.63\right.$ for $\tau=10 \mathrm{~d}$ ). This is mainly due to the greater intensity of deep convection in the tropics, and is reflected in the good correlation $\left(r^{2}=0.63\right)$ between $E_{\mathrm{UT}}$ and the parameterized convective mass flux through $5 \mathrm{~km}$ altitude in the MPC source column for the $\tau=10 \mathrm{~d}$ tracers. For $\tau=1 \mathrm{~d}$ the correlation improves to $r^{2}=0.81$, while for the $\tau=100 \mathrm{~d}$ tracers it is much poorer $\left(r^{2}=0.32\right)$, as could be expected due to the less important role of episodic convective mixing for longer-lived tracers.

\subsubsection{Specific MPC features}

The potential for transporting short and intermediate lifetime insoluble pollutants to the UT is substantial for several of the MPCs. For the $\tau=10 \mathrm{~d}$ tracers, there are 6 source loca- tions with $>50 \%$ of the tracer mass in the UT, all in either Southeast Asia or tropical South America: Jakarta, Manila, Bangkok, Sao Paulo, Rio de Janeiro, and Bogota. Even for the $\tau=1 \mathrm{~d}$ tracers, these six MPCs plus one other (Lagos) have $>30 \%$ of the tracer mass in the UT. At the other end of the spectrum, the lowest seven ranked MPCs for $E_{\mathrm{UT}}$ are all in Eurasia and northern Africa, with an average $E_{\mathrm{UT}}$ of $13.7 \%$.

As for $E L R_{1 \mathrm{~km}}$, there is a notable intraregional variability for several of the MPCs. A clear anti-correlation between $E_{\mathrm{UT}}$ and the absolute latitude of the MPCs was noted above; the intraregional variability is reflected in several outliers to this anti-correlation. On the high side are MPCs where stronger convection than expected for that latitude prevails throughout much of the year, including Sao Paulo, Rio de Janeiro, Tokyo, Osaka, Manila, and Bangkok. On the low side are cities where convection is suppressed, especially Cairo and Teheran in the downward branch of the Hadley Cell. For Cairo, only half as much makes it to the UT as would be expected from the linear regression on the latitude.

One of the clearest intraregional difference is in southern Asia, which is detailed in Fig. 9. This could be anticipated 
from the gradient in annual mean convective mass fluxes through $500 \mathrm{hPa}$ (Fig. 4). The stronger mass fluxes towards the east and the Bay of Bengal result in a notably stronger upwards transport of pollution from Kolkata and Dhaka $\left(E_{\mathrm{UT}}=36.8-39.2 \%\right)$ than from Karachi, Mumbai, and Delhi (22.5-27.6\%), which are in the same latitude range but some $15-20^{\circ}$ to the west, with the difference growing larger for the cities farther to the west. There are also a few other notable intraregional differences. In South America, the Brazilian MPCs and Bogota are much more efficient exporters to the UT ( $\left.E_{\mathrm{UT}}=50.4-55.3 \%\right)$ than Lima and Buenos Aires (26.5-31.2\%), and the difference noted in the previous section between Sydney and Melbourne is seen here as well, with a factor of two difference between the $E_{\mathrm{UT}}$ values of $34.5 \%$ and $17.2 \%$, respectively.

On the whole, the results from these individual MPCs are reflected in a strong anti-correlation between the full set of $E_{\mathrm{UT}}$ and $E L R_{1 \mathrm{~km}}$, with $r^{2}=0.82$ for the values, and $r^{2}=0.89$ for the rankings (for the $\tau=10 \mathrm{~d}$ tracers). Thus, vertical transport by convection is a major factor in reducing long-range low-level export. A remaining question is how this interplay between vertical and long-range horizontal transport affect the buildup of pollution in the surface layer of the regions surrounding the MPCs, which is addressed in the following sections.

\subsection{Regional exceedances of density thresholds}

\subsubsection{General results}

The effects of pollutants on humans and agriculture depends on the amount of the pollutant present (in terms of either the density, concentration or mixing ratio), though the exact dependence differs for each pollutant, in terms of both the critical amounts and the exposure time-scales. In this section we examine a regional pollution potential metric which indicates the anticipated degree of widespread exposure to elevated pollutant levels above a chosen threshold density, in the outflow of each MPC. We focus on the three threshold densities 1,10 , and $100 \mathrm{ng} / \mathrm{m}^{3}$ (i.e., $A_{1}, A_{10}$, and $A_{100}$ ), which we find to be appropriate for characterizing and comparing the outflow of the tracers with all three lifetimes. The physical meaning of these metrics is shown graphically in Figs. 7 and 8 for Delhi and Moscow, and for the remaining MPCs in the electronic supplement, in which $A_{1}$ is represented by the area enclosed by the light violet shading, $A_{10}$ is the area enclosed by the light blue shading, and $A_{100}$ is the area enclosed by the light green shading.

The values for one of these metrics, $A_{10}$, are given in Table 4 for the $\tau=10 \mathrm{~d}$ tracer. The values range over more than an order of magnitude, from $0.4-11.1 \times 10^{6} \mathrm{~km}^{2}$, offering a good separation between the MPCs. The MPCs which show the most extensive surface-layer pollution buildup around the source region include those in Europe, western Asia, northern Africa, eastern China, and eastern North America, and
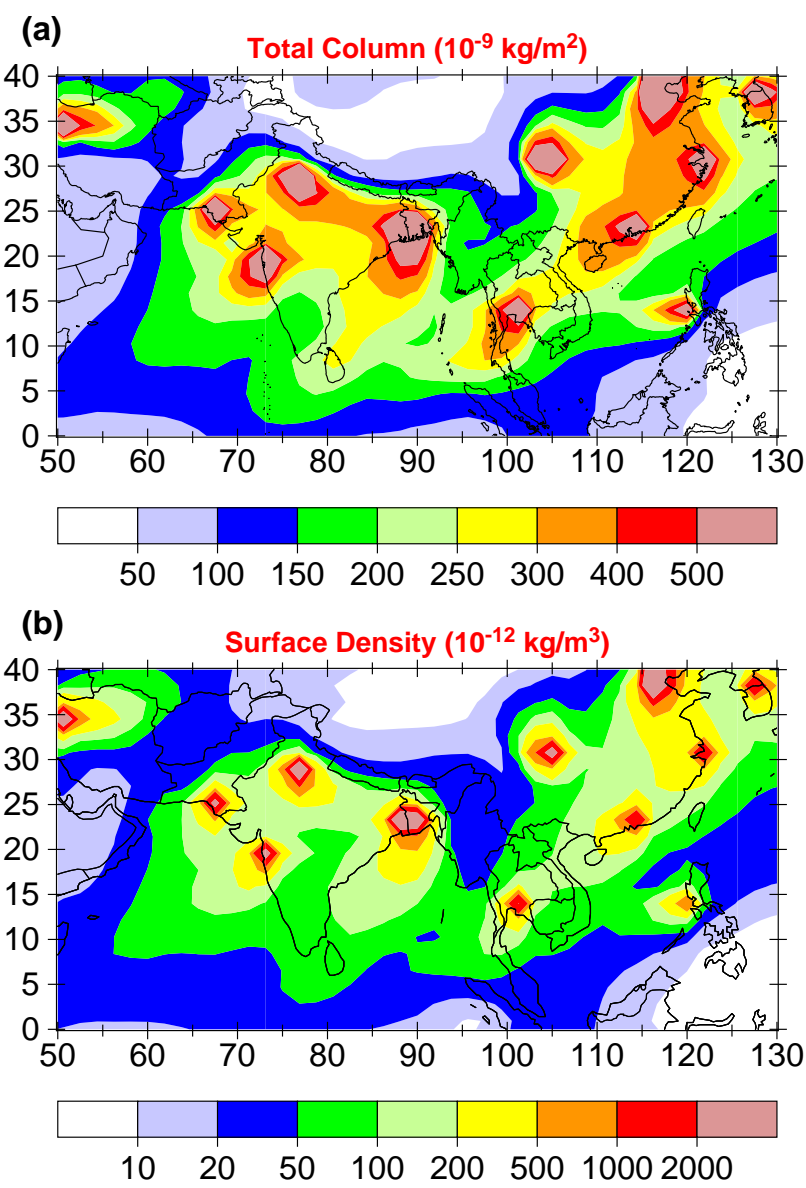

(c) Upper Tropospheric Column, above $5 \mathrm{~km}\left(10^{-9} \mathrm{~kg} / \mathrm{m}^{2}\right)$

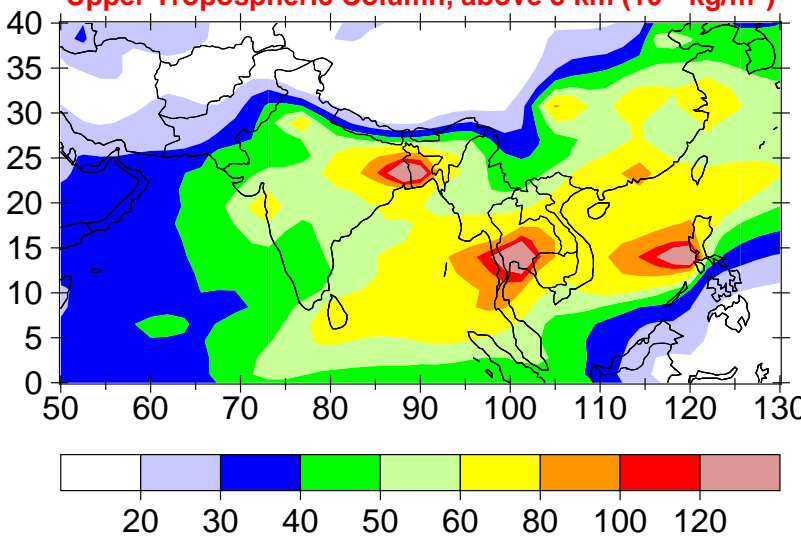

Fig. 9. Like Fig. 1, except zoomed in on the southern Asian region: (a) the total column mass density $\left(10^{-9} \mathrm{~kg} / \mathrm{m}^{2}\right)$, (b) the model surface layer density $\left(10^{-12} \mathrm{~kg} / \mathrm{m}^{3}\right)$, and (c) the column above $5 \mathrm{~km}$ $\left(10^{-9} \mathrm{~kg} / \mathrm{m}^{2}\right)$.

the least effective MPCs in the annual mean include those in Southeast Asia, Mexico City, the South American cities of Bogota, Rio de Janeiro and Sao Paulo, the central and southern African cities of Lagos and Johannesburg, and the Szechuan Basin in China. 
Table 5. Mean surface areas $\left(10^{6} \mathrm{~km}^{2}\right)$ with densities exceeding the stated threshold for the given tracer lifetimes (minimum and maximum values are given in parentheses).

\begin{tabular}{lccc}
\hline Tau (d) & $100 \mathrm{ng} / \mathrm{m}^{-3}$ & $10 \mathrm{ng} / \mathrm{m}^{-3}$ & $1 \mathrm{ng} / \mathrm{m}^{-3}$ \\
\hline Total (All Surfaces) & & & \\
1 & $0.19(0.04-0.35)$ & $0.90(0.22-1.75)$ & $3.22(0.43-6.50)$ \\
10 & $0.42(0.13-1.13)$ & $4.09(0.39-11.09)$ & $24.37(8.50-58.26)$ \\
100 & $0.52(0.13-1.57)$ & $11.58(0.60-52.00)$ & $309.47(270.53-401.86)$ \\
Continental & & & \\
1 & $0.16(0.04-0.35)$ & $0.60(0.14-1.75)$ & $1.80(0.21-5.29)$ \\
10 & $0.32(0.07-1.13)$ & $2.36(0.21-10.50)$ & $11.44(1.25-48.74)$ \\
100 & $0.39(0.07-1.57)$ & $6.38(0.38-45.34)$ & $120.64(61.15-148.75)$ \\
\hline
\end{tabular}

A summary of the mean values and ranges of $A_{1}, A_{10}$, and $A_{100}$ for the MPC tracers with the three lifetimes $(\tau=1 \mathrm{~d}$, $10 \mathrm{~d}$ and $100 \mathrm{~d}$ ) is given in Table 5 for all surface types (land and sea), as well as for the outflow only over continental surfaces. Since these are linear tracers, these threshold densities will scale with the source magnitude; e.g., for a source of $1000 \mathrm{~kg} / \mathrm{s}$, the threshold densities would be 1,10 , and $100 \mu \mathrm{g} / \mathrm{m}^{3}$. Note, however, that this can only be applied directly for pollutants which do not affect their own loss frequencies; for cases where chemical feedbacks are important, such as CO (Prather, 1996) and $\mathrm{NO}_{\mathrm{x}}$ (Kunhikrishnan and Lawrence, 2004), a simple scaling like this is not possible.

Table 5 shows that, for our case with a source of $1 \mathrm{~kg} / \mathrm{s}$ for each tracer, the chosen range of threshold densities (1$100 \mathrm{ng} / \mathrm{m}^{3}$ ) separates the densities which are generally only found on local to regional scales $\left(<10^{6} \mathrm{~km}^{2}\right)$ and the densities which are normally computed to be spread over continental scales $\left(>10^{6} \mathrm{~km}^{2}\right)$. The threshold density of $100 \mathrm{ng} / \mathrm{m}^{3}$ is only exceeded over limited regions, with $A_{100}$ being less than $10^{6} \mathrm{~km}^{2}$ for all tracers (with the one exception being Moscow), and averaging about $0.5 \times 10^{6} \mathrm{~km}^{2}$ or less, depending on the lifetime (equivalent to a radius of expansion of $\leq 400 \mathrm{~km}$ ). On the other hand, the lower threshold density of $1 \mathrm{ng} / \mathrm{m}^{3}$ is exceeded over regions much larger than $10^{6} \mathrm{~km}^{2}$ for all of the tracers (with the single exception of the $\tau=1 \mathrm{~d}$ tracer for Bogota), averaging up to more than $300 \times 10^{6} \mathrm{~km}^{2}$ for the $\tau=100 \mathrm{~d}$ tracers.

The strong concentration of the $\tau=1 \mathrm{~d}$ tracers versus the extensive dispersion of the $\tau=100 \mathrm{~d}$ tracers can be seen quantitatively by comparing the values in Table 5 with the theoretical maximum areas which could be covered by the tracers for each combination of threshold density and lifetime (assuming instantaneous mixing). For the $\tau=100 \mathrm{~d}$ tracers, the mean value of $A_{1}$ is fairly close to the maximum possible value of about $864 \times 10^{6} \mathrm{~km}^{2}$ (computed assuming the tracers are well-mixed up to $10 \mathrm{~km}$ altitude), whereas the extensive dispersion of the long-lived tracers reduces the mean value of $A_{100}$ to less than a tenth of its potential maximum of $8.64 \times 10^{6} \mathrm{~km}^{2}$. The opposite is the case for the $\tau=1 \mathrm{~d}$ tracers. In this case, the strong concentration of these short- lived tracers around their source locations results in a mean value for $A_{100}$ that is nearly a fourth of the maximum possible value $\left(0.864 \times 10^{6} \mathrm{~km}^{2}\right.$, assuming for this case a mixing depth of $1 \mathrm{~km}$ altitude), whereas the limited dispersion reduces $A_{1}$ to only about $4 \%$ of the maximum possible value $\left(86.4 \times 10^{6} \mathrm{~km}^{2}\right)$.

As for $E L R_{1 \mathrm{~km}}$, an additional relevant characteristic is how much of the regional pollution buildup is over land, and how much is over the oceans. Table 5 shows that for the lower threshold density $\left(1 \mathrm{ng} / \mathrm{m}^{3}\right)$, like for $E L R_{1 \mathrm{~km}}$ the proximity of most of the MPCs to coasts results in a reduction of the mean value of $A_{1}$ by about one half. For the higher threshold of $100 \mathrm{ng} / \mathrm{m}^{3}$, however, there is only a small difference between the mean $A_{100}$ for land only and for all surfaces, since the regional coverage is generally limited to the area very closely surrounding the MPCs.

Finally, as for the other metrics, we can expect $A_{10}$ (and likewise $A_{1}$ and $A_{100}$ ) to vary as a function of the tracer lifetime and the chosen threshold density. Focusing on the source grid cell, interestingly, the maximum mixing ratios computed for the tracers do not differ much. These are 3.3, 4.8 and $4.5 \mu \mathrm{g} / \mathrm{m}^{3}$ for the $\tau=1,10$ and $100 \mathrm{~d}$ lifetime tracers, in all cases much lower than the theoretical maximum of $225-435 \mu \mathrm{g} / \mathrm{m}^{3}$ if all the emissions of a given tracer were to remain concentrated only in the source cell. Since the source rate is the same $(1 \mathrm{~kg} / \mathrm{s})$ for all three lifetimes, this indicates that the tracer density near the source depends primarily on the dispersion rate, rather than on the lifetime of the tracer within the range considered, $\tau=1-100 \mathrm{~d}$ (that is, the modeled dispersion of air away from the source is occurring on time-scales of the order of a day or less). However, it is important to note that transport at the single grid cell scale is difficult to resolve, and it would be valuable to have a confirmation of this conclusion in a future study using a regional model.

The overall importance of tracer lifetime on larger scales is seen in Fig. 2, which shows the substantial difference in local pollution buildup versus long-range export due to the different lifetimes. Since the contours have been chosen to reflect the ratios between the total global masses of the tracers, if the 
tracers were distributed similarly, despite their different total masses, the figures would look the same. The differences in the panels directly reflect the greater degree of dispersion of the longer-lived tracers. A key question, given these differences in dispersion, is whether or not the rankings tend to be similar for the various lifetimes. On the whole this is indeed the case, especially for the two longer-lived tracers; for example, for the metric $A_{10}$ listed in Table 4, the correlations and deviations between the rankings of the $\tau=1 \mathrm{~d}$ and $\tau=10 \mathrm{~d}$ tracers are $r^{2}=0.67$, rms $=6.3$, and between the $\tau=10 \mathrm{~d}$ and $\tau=100 \mathrm{~d}$ tracers are $r^{2}=0.83, \mathrm{rms}=4.3$.

\subsubsection{Specific MPC features}

There are several notable intraregional differences in $A_{10}$ for the $\tau=10 \mathrm{~d}$ tracers. As noted above, for the case of Eurasia this is largely due to differences in deep convective mass fluxes, removing tracers from the BL. Four of the Eurasian MPCs have very high ranks (London - 2, Paris - 3, Moscow -1 , Cairo - 5), while three are ranked much lower (Po Valley -13 , Istanbul -11 , Teheran -18 ), and there there is a very good anti-correlation between the values of $E_{\mathrm{UT}}$ and $A_{10}\left(r^{2}=0.83\right.$, or $r^{2}=0.76$ if Moscow is not included as an extreme case).

Another intraregional difference, which was not noted as clearly in the other metrics, is in eastern Asia, where Tianjin, Beijing and Shanghai are ranked 6-8 for $A_{10}$, while Seoul, Tokyo, and Osaka are ranked 20-26. In this case, the difference is not due to the vertical transport by convection, rather to differences in the surface wind flow, as depicted in Fig. 5. The contrast is particularly evident for Tianjin and Seoul ("T" and "S" on the figure), which are at about the same model latitude and about $10^{\circ}$ apart in longitude, and have values of $E_{\mathrm{UT}}$ which are very close (25.6 and 27.1\%). However, the much lower wind speeds near Tianjin allow considerably more local pollution buildup to a much larger value for $A_{10}$ than for the Seoul tracer (6.1 vs. $\left.4.2 \times 10^{6} \mathrm{~km}^{2}\right)$.

3.4 Relationship between long-range low-level export and local to regional pollution buildup

The metrics discussed in the previous three sections can be used in tandem to examine the relative roles of horizontal versus vertical transport in determining pollutant export and local to regional pollution buildup around the MPCs. If the vertical mixing were to be the same for two MPCs, then one would expect that more efficient long-range export would tend to dilute the tracer near its source, resulting in smaller regions with elevated tracer densities and thus an anti-correlation between $E L R_{1} \mathrm{~km}$ and $A_{x}$ (with $x=1,10$, or 100). On the other hand, increased vertical mixing out of the BL can lead to a simultaneous reduction in both $E L R_{1 \mathrm{~km}}$ and $A_{x}$, resulting in a correlation between the two if there are very large differences in vertical mixing between a set of MPCs.

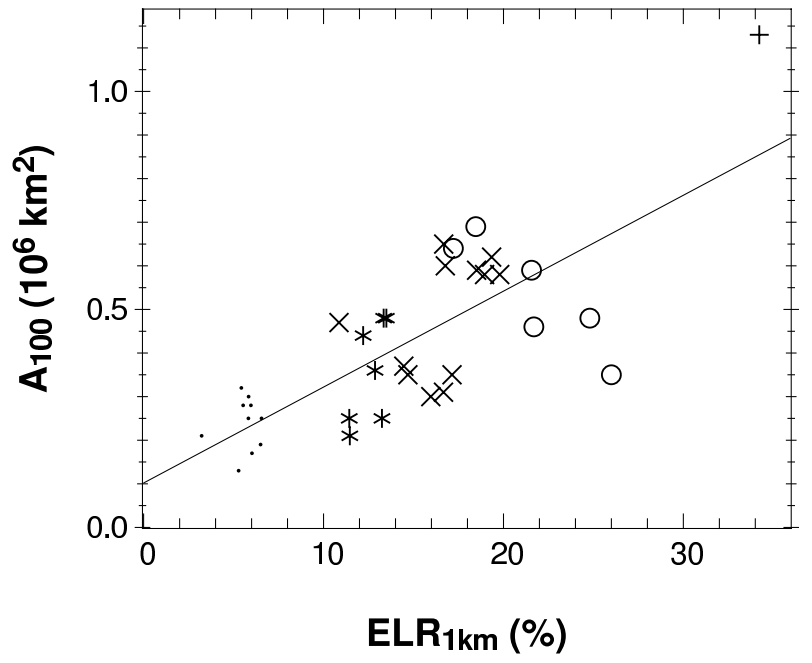

Fig. 10. Scatter plot and least squares regression line between the annual mean values of $A_{100}$ and $E L R_{1 \mathrm{~km}}$ for the $\tau=10 \mathrm{~d}$ tracers; the points are coded by their ranks for $E_{\mathrm{UT}}$, with the symbols: points $(\cdot)$ for the top 10 ranked MPCs, stars $(*)$ for the MPCs ranked 11-17, crosses $(\times)$ for ranks 18-29, circles (o) for ranks 30-35, and a plus (+) for the outlier Moscow (rank 36).

The relationship between $E L R_{1 \mathrm{~km}}$ and $A_{100}$ is shown in Fig. 10. We focus on the $\tau=10 \mathrm{~d}$ tracers here, for which we expect the relationships to be stronger than for the $\tau=1 \mathrm{~d}$ and $\tau=100 \mathrm{~d}$ tracers, since convective mixing time-scales in the atmosphere are of the order of 10 days (WMO, 2002); however, the main points discussed here also largely apply to the longer and shorter lived tracers as well. Since we are interested in separating the behavior at local to regional versus continental export scales, we focus on $A_{100}$, which is limited to an area equivalent to less than a $1000 \mathrm{~km}$ radius circle for all of the tracers (see Table 5). To additionally consider the influence of vertical mixing, the points are coded by different symbols for different values of $E_{\mathrm{UT}}$.

The figure nicely shows the influences of both horizontal and vertical mixing. In particular, for the Eurasian MPCs excluding Moscow (the circles), which have the overall weakest vertical transport $\left(E_{\mathrm{UT}}=11.7-16.7 \%\right)$, there is a very strong anti-correlation between $E L R_{1} \mathrm{~km}$ and $A_{100}\left(r^{2}=0.80\right)$. Interestingly, the next set of tracers in terms of values of $E_{\mathrm{UT}}$ (crosses) divide themselves up into two distinct groups, one clustering with the circles (with $E_{\mathrm{UT}}$ ranging from 22.0 $32.7 \%)$, the other with the stars $\left(E_{\mathrm{UT}}=22.5-31.2 \%\right)$. We have not yet been able to determine a clear reason for this split, but do note that the latter group includes mostly MPCs which are near major coastal export regions (e.g., Seoul, discussed in the previous section), whereas the former group tends to be more inland or have a weaker outflow to maritime regions (e.g., Tianjin), and thus the difference between the depth of the continental and marine boundary layers may play a role in this split. Considering these two groups of 
MPCs individually, both also show an anti-correlation between $E L R_{1 \mathrm{~km}}$ and $A_{100}\left(r^{2}=0.34\right.$ and $r^{2}=0.81$, respectively), again demonstrating the importance of horizontal transport differences between these MPCs.

On the other hand, once the vertical transport becomes more substantial $\left(E_{\mathrm{UT}}>33 \%\right.$, stars and points), the anticorrelation between $E L R_{1 \mathrm{~km}}$ and $A_{100}$ breaks down. The overall importance of the large variability in vertical transport between the MPCs can be seen by comparing the clusters of the different symbols, which show a decrease in both $E L R_{1 \mathrm{~km}}$ and $A_{100}$ with an increasing $E_{\mathrm{UT}}$. Considering the full set of MPCs, there is a relatively good correlation between $E L R_{1 \mathrm{~km}}$ and $A_{100}\left(r^{2}=0.60\right)$, as well as an anti-correlation between $E_{\mathrm{UT}}$ and $E L R_{1 \mathrm{~km}}$ (noted above, $\left.r^{2}=0.82\right)$ and between $E_{\mathrm{UT}}$ and $A_{100}\left(r^{2}=0.45\right)$. Thus, from a global perspective, it is the transport into the free and upper troposphere, rather than long-range horizontal transport, which is primarily responsible for diluting the surface-layer pollutant levels near their source locations, though for specific regions, or for MPCs in different regions with similar vertical transport characteristics, the trade-off between longrange horizontal export and dilution of pollutants in the region surrounding their sources becomes evident.

\section{Conclusions}

This study has taken several steps towards developing an overall understanding of the characteristics of pollutant outflow, long-range pollutant export and regional pollution buildup for emissions from major population centers (MPCs) distributed around the world. The MPCs have been represented as large point sources of tracers with different lifetimes. Our analysis has focused particularly on bringing out the tradeoffs between local and regional near-surface pollutant buildup, low-level long-range export to neighboring regions and states, and export to the UT and potentially the lower stratosphere, each as a function of the source location.

For this study, we have developed a new approach for examining the comparative characteristics of pollutant dispersion from MPCs, by defining a set of various metrics targeting examination of different outflow and regional pollution buildup characteristics. In principle, the same approach could be applied to future model studies of other source types, such as forest fires (e.g. Heald et al., 2003) and power plants (e.g. Marufu et al., 2004). Since we have employed simple tracers with equal source strengths for all MPCs, the focus has been on the generic meteorological outflow characteristics, rather than specific gases and aerosols. A few implications of the results for real world tracers were noted in the text, and further implications for ozone and related gases are discussed in Butler et al. (2007b) ${ }^{2}$.

Using the chosen set of tracers and metrics, we have provided first quantifications for several of the outflow characteristics:
1. Long-range near-surface pollutant export is generally strongest in the middle and high latitudes, especially for Moscow and other source locations in Eurasia; for these regions, $E L R_{1 \mathrm{~km}}$ for the $\tau=10 \mathrm{~d}$ tracers ranges from 17-34\%, contrasted with tropical MPCs with $E L R_{1 \mathrm{~km}}$ as low as $3-5 \%$;

2. Pollutant export to the upper troposphere is greatest in the tropics, especially from Jakarta and other Southeast Asian MPCs, due to transport by deep convection; for the $\tau=10 \mathrm{~d}$ tracers $E_{\mathrm{UT}}$ exceeds $50 \%$ for six MPCs, and $30 \%$ for 19 MPCs, contrasted with less than $10 \%$ of the mass residing above $5 \mathrm{~km}$ altitude for the Moscow tracer;

3. The tendency for major cities to develop near coasts is reflected in the computation that over half of the longrange low-level export occurs over the oceans: the mean value of $E L R_{1 \mathrm{~km}}$ (for $\tau=10 \mathrm{~d}$ ) is $14.1 \%$ over all surfaces, and $6.4 \%$ when only continental surfaces are considered;

4. Not only are there order of magnitude interregional differences, such as between low and high latitudes, but also often substantial intraregional differences; one example is the difference between the mean $E_{\mathrm{UT}}$ (for $\tau=10 \mathrm{~d}$ ) for the MPCs in western India and Pakistan $(38 \%)$ versus eastern India and Bangladesh $(25 \%)$, due to the longitudinal gradient in the intensity of the monsoon convection;

We also examined the relative roles of horizontal and vertical transport in controlling the tradeoffs between different characteristics of export and regional pollution buildup. Our simulations show that for specific regions like Eurasia, as expected, the dilution due to long-range low-level horizontal export (e.g., to beyond $1000 \mathrm{~km}$ ) results in a reduction in the buildup of pollution in the surface layer surrounding the source location (within $1000 \mathrm{~km}$ ). However, vertical transport can also play a contrasting role: in regions where vertical transport is strong, both the long-range low-level export and the regional pollution buildup surrounding the source are reduced, compared to the enhancement of both in regions in which vertical transport is weak. For the full set of MPCs, we compute that the long-range low-level export $\left(E L R_{1 \mathrm{~km}}\right)$ is well-correlated with the areas exceeding a relatively high surface density threshold $\left(A_{100}\right)$, indicating that, on a global basis, the vertical transport effect is dominant. In turn, this points to the need for further research on vertical transport processes in order to arrive at a better understanding of pollution characteristics in major population centers and their surrounding and further downwind regions. This applies particularly to deep convection, which was found to correlate well with the export metrics, as well as to other processes that vent air pollution from the BL, including diurnal BL height changes and small-scale effects such as land-sea breezes. 
The key caveats to these results are that they are based on model simulations which cannot resolve many critical processes such as boundary layer turbulence and convection, and that a direct comparison with observations is not possible, since the study focuses on carefully-chosen tracers with representative characteristics. Nevertheless, as mentioned above, we have evidence through previous studies with MATCH in comparison to field observations that the model is able to represent pollutant outflow well at these scales in many different geographical regions, including outflow from North America, Europe, and southern Asia.

As an outlook, there are several questions which could be addressed in future studies, either with comparable models to MATCH, or after further model developments (e.g., substantial improvements in resolution or transport parameterizations), which would add to the initial overview of MPC regional pollution potentials developed in this study, for instance:

- What additional information could be gained if the tracer results were convolved with maps of population or agricultural distributions?

- How do physical deposition processes (surface uptake and precipitation scavenging) affect the pollution potentials, and what additional metrics might be sensible for examining the variability in regional deposition intensities?

- How do the long-range export potentials differ, especially for shorter-lived gases, when they are released above the surface layer (e.g., at a few hundred meters altitude from tall smoke stacks)?

- How are the results affected when the lifetime increases with altitude, as is characteristic of many real trace gases and aerosols?

- How great is the inter-annual variability in the pollution potential metrics?

- How do the regional pollution potentials change with future changes in climate and meteorology?

- How do the results depend on the model resolution, and eventually on the ability to better resolve orographic features and small-scale circulation effects such as the land-sea breeze (particularly relevant for the many coastal MPCs) and the urban heat island (which will enhance local vertical mixing)?

Finally, it would be worthwhile to consider a model intercomparison exercise to help make the results more robust, and to elucidate where the largest uncertainties in the model results are. A particularly enlightening step would be to involve regional models in such an intercomparison, in which the regional models would simulate MPC tracers which exactly replicate those used in the global models, i.e., emitted uniformly over a region representing the global model grid cell for each MPC, and with the same decay constants. This would especially help to document how future improvements in the parameterizations of vertical mixing by boundary layer diffusion and deep convection influence the computed characteristics of MPC pollutant dispersion.

Acknowledgements. We enjoyed early discussions on this and our related megacities work with P. Crutzen and J. van Aardenne, and we acknowledge P. Rasch for the long-term support of MATCH. We are grateful for the thorough and constructive comments of the three anonymous referees and the editor, Y. Balkanski. This work was largely supported by funding from the German Ministry of Education and Research (BMBF), project 07-ATC-02. B. R. Gurjar was additionally supported by the MPI-Chemistry and the Max Planck Society Partner Group for Megacities and Global Change, established at IIT-Roorkee, India.

Edited by: Y. Balkanski

\section{References}

Akimoto, H.: Global air quality and pollution, Science, 302, 17161719, 2003.

Chameides, W. L., Kasibhatla, P. S., Yienger, J., and II, H. L.: Growth of continental-scale metro-agro-plexes, regional ozone pollution, and world food production, Science, 264, 74-77, 1994.

Crutzen, P. J. and Lawrence, M. G.: The Impact of Precipitation Scavenging on the Transport of Trace Gases: A 3-dimensional Model Sensitivity Study, J. Atmos. Chem., 37, 81-112, 2000.

de Foy, B., Varela, J. R., Molina, L. T., and Molina, M. J.: Rapid ventilation of the Mexico City basin and regional fate of the urban plume, Atmos. Chem. Phys., 6, 2321-2335, 2006, http://www.atmos-chem-phys.net/6/2321/2006/.

Emberson, L., Ashmore, M., Murray, F., Kuylenstierna, J., Percy, K., Izuta, T., Zheng, Y., Shimizu, H., Sheu, B., Liu, C., Agrawal, M., Wahid, A., Abdel-Latif, N., van Tienhoven, M., de Bauer, L., and Domingos, M.: Impacts of air pollutants on vegetation in developing countries, Water, Air Soil Pollut., 130, 107-118, 2001.

Gros, V., Williams, J., van Aardenne, J. A., Salisbury, G., Hofmann, R., Lawrence, M. G., von Kuhlmann, R., Lelieveld, J., Krol, M. Berresheim, H., Lobert, J. M., and Atlas, E.: Origin of anthropogenic hydrocarbons and halocarbons measured in the summertime European outflow (on Crete in 2001), Atmos. Chem. Phys., 3, 1223-1235, 2003, http://www.atmos-chem-phys.net/3/1223/2003/.

Gros, V., Williams, J., Lawrence, M. G., von Kuhlmann, R., van Aardenne, J. A., Atlas, E., Chuck, A., Edwards, D. P., Stroud, V., , and Krol, M.: Tracing the origin and ages of interlaced atmospheric pollution events over the tropical Atlantic Ocean with in-situ measurements, satellites, trajectories, emission inventories and global models, J. Geophys. Res., 109, D22306, doi:10.1029/2004JD004846, 2004.

Gurjar, B. and Lelieveld, J.: New Directions: Megacities and global change, Atmos. Environ., 39, 391-393, 2005. 
Gurjar, B., van Aardenne, J., Lelieveld, J., and Mohan, M.: Emission estimates and trends (1990-2000) for megacity Delhi and implications, Atmos. Environ., 38, 5663-5681, 2004.

Guttikunda, S., Tang, Y., Carmichael, G., Kurata, G., Pan, L., Streets, D., Woo, J.-H., Thongboonchoo, N., and Fried, A.: Impacts of Asian megacity emissions on regional air quality during spring 2001, J. Geophys. Res., 110, D20301, doi:10.1029/2004JD004921, 2005.

Heald, C., Jacob, D., Palmer, P., Evans, M., Sachse, G., Singh, H., and Blake, D.: Biomass burning emission inventory with daily resolution: Application to aircraft observations of Asian outflow, J. Geophys. Res., 108, 8811, doi:10.1029/2002JD003082, 2003.

Kalnay, E., Kanamitsu, M., Kistler, R., Collins, W., Deaven, D., Gandin, L., Iredell, M., Saha, S., White, G., Woollen, J., Zhu, Y., Chelliah, M., Ebisuzaki, W., Higgins, W., Janowiak, J., Mo, K. C., Ropelewski, C., Wang, J., Leetmaa, A., Reynolds, R., Jenne, R., and Joseph, D.: The NCEP/NCAR 40-year reanalysis project, Bull. Am. Meteor. Soc., 77, 437-471, 1996.

Kiehl, J. T., Bonan, G. B., Boville, B. A., Briegleb, B. P., Williamson, D. L., and Rasch, P. J.: Description of the NCAR Community Climate Model (CCM3), NCAR Tech. Note NCAR /TN-420+STAR, Nat. Cent. Atmos. Res., Boulder, CO, 1996.

Kunhikrishnan, T. and Lawrence, M. G.: Sensitivity of $\mathrm{NO}_{2}$ over the Indian Ocean to emissions from the surrounding continents and nonlinearities in atmospheric chemistry responses, Geophys. Res. Lett., 31, L15109, doi:10.1029/2003GL020210, 2004.

Lacis, A. A., Wuebbles, D. J., and Logan, J. A.: Radiative forcing of climate by changes in the vertical distribution of ozone, J. Geophys. Res., 95, 9971-9981, 1990.

Lang, R. and Lawrence, M. G.: Evaluation of the hydrological cycle of MATCH driven by NCEP reanalysis data: comparison with GOME water vapor field measurements, Atmos. Chem. Phys., 5, 887-908, 2005a.

Lang, R. and Lawrence, M. G.: Improvement of the vertical humidity distribution in the chemistry-transport model MATCH through increased evaporation of convective precipitation, Geophys. Res. Lett., 32, L17812, doi:10.1029/2005GL023172, $2005 b$.

Lawrence, M. G. and Rasch, P. J.: Tracer transport in deep convective updrafts: plume ensemble versus bulk formulations, J. Atmos. Sci., 62, 2880-2894, 2005.

Lawrence, M. G., Crutzen, P. J., Rasch, P. J., Eaton, B. E., and Mahowald, N. M.: A model for studies of tropospheric photochemistry: Description, global distributions, and evaluation, J. Geophys. Res., 104, 26 245-26 277, 1999.

Lawrence, M. G., Rasch, P. J., von Kuhlmann, R., Williams, J., Fischer, H., de Reus, M., Lelieveld, J., Crutzen, P. J., Schultz, M., Stier, P., Huntrieser, H., Heland, J., Stohl, A., Forster, C., Elbern, H., Jakobs, H., and Dickerson, R. R.: Global chemical weather forecasts for field campaign planning: predictions and observations of large-scale features during MINOS, CONTRACE, and INDOEX, Atmos. Chem. Phys., 3, 267-289, 2003 a.

Lawrence, M. G., von Kuhlmann, R., Salzmann, M., and Rasch, P. J.: The balance of effects of deep convective mixing on tropospheric ozone, Geophys. Res. Lett., 30, 1940, doi:10.1029/2003GL017644, 2003b.

Lelieveld, J., Crutzen, P. J., Ramanathan, V., Andreae, M. O., Brenninkmeijer, C. A. M., Campos, T., Cass, G. R., Dickerson, R. R., Fischer, H., de Gouw, J. A., Hansel, A., Jefferson, A., Kley, D., de Laat, A. T. J., Lal, S., Lawrence, M. G., Lobert, J. M., MayolBracero, O. L., Mitra, A. P., Novakov, T., Oltmans, S. J., Prather, K. A., Reiner, T., Rodhe, H., Scheeren, H. A., Sikka, D., and Williams, J.: The Indian Ocean Experiment: Widespread Air Pollution from South and Southeast Asia, Science, 291, 10311036, 2001.

Lohmann, U.: A glaciation indirect aerosol effect caused by soot aerosols, Geophys. Res. Lett., 29, 1052, doi:10.1029/2001GL014357, 2002.

Mahowald, N. M., Prinn, R., and Rasch, P. J.: Deducing $\mathrm{CCl}_{3} \mathrm{~F}$ emissions using an inverse method and chemical transport models with assimilated winds, J. Geophys. Res., 102, $28153-$ 28 168, 1997a.

Mahowald, N. M., Rasch, P. J., Eaton, B. E., Whittlestone, S., and Prinn, R. G.: Transport of ${ }^{222}$ radon to the remote troposphere using the Model of Atmospheric Transport and Chemistry and assimilated winds from ECMWF and the National Center for Environmental Prediction/NCAR, J. Geophys. Res., 102, 28 13928 152, 1997b.

Marufu, L. T., Taubman, B. F., Bloomer, B., Piety, C. A., Doddridge, B. G., Stehr, J. W., and Dickerson, R. R.: The 2003 North American electrical blackout: An accidental experiment in atmospheric chemistry, Geophys. Res. Lett., 31, L13106, doi:10.1029/2004GL019771, 2004.

Molina, M. J. and Molina, L. T.: Megacities and atmospheric pollution, J. Air Waste Manage. Assoc., 54, 644-680, 2004.

National Imagery and Mapping Agency, http://earth-info.nga.mil/ GandG/publications/tr8350.2/wgs84fin.pdf, Tech. rep, 2000.

Pfister, G., Petron, G., Emmons, L., Gille, J., Edwards, D., Lamarque, J., Attie, J., Granier, C., and Novelli, P.: Evaluation of CO simulations and the analysis of the CO budget for Europe, J. Geophys. Res., 109, D19304, doi:10.1029/2004JD004691, 2004.

Prather, M. J.: Time scales in atmospheric chemistry: Theory, GWPs for $\mathrm{CH}_{4}$ and $\mathrm{CO}$, and runaway growth, Geophys. Res. Lett., 23, 2597-2600, 1996.

Ramanathan, V., Crutzen, P. J., Mitra, A. P., and Sikka, D.: The Indian Ocean Experiment and the Asian Brown Cloud, Curr. Sci., 83, 947-955, 2002.

Rasch, P. J., Mahowald, N. M., and Eaton, B. E.: Representations of transport, convection and the hydrologic cycle in chemical transport models: Implications for the modeling of short lived and soluble species, J. Geophys. Res., 102, 28 127-28 138, 1997.

Salisbury, G., Williams, J., Holzinger, R., Gros, V., Mihalopoulos, N., Vrekoussis, M., Sarda-Estève, R., Berresheim, H., von Kuhlmann, R., Lawrence, M., and Lelieveld, J.: Ground-based PTR-MS measurements of reactive organic compounds during the MINOS campaign in Crete, July-August 2001, Atmos. Chem. Phys., 3, 925-940, 2003, http://www.atmos-chem-phys.net/3/925/2003/.

Stohl, A.: A 1-year lagrangian "climatology" of airsteams in the Northern Hemisphere troposphere and lowermost stratosphere, J. Geophys. Res., 106, 7263-7279, 2001.

Stohl, A., Eckhardt, S., Forster, C., James, P., and Spichtinger, N.: On the pathways and timescales of intercontinental air pollution transport, J. Geophys. Res., 107, 4684, doi:10.1029/2001JD001396, 2002.

von Kuhlmann, R., Lawrence, M. G., Crutzen, P. J., and Rasch, P. J.: A model for studies of tropospheric ozone and non-methane hydrocarbons: Model description and ozone results, J. Geophys. 
Res., 108, 4294, doi:10.1029/2002JD002893, 2003.

Wild, O. and Akimoto, H.: Intercontinental transport ozone and it precursors in a three-dimensional global CTM, J. Geophys. Res., 106, 27 729-27 744, 2001.
WMO: Scientific Assessment of Ozone Depletion: 2002, Global ozone research and monitoring project - report no. 47, 498 pp., WMO, Geneva, 2002. 